\title{
Epac activation, altered calcium homeostasis and ventricular arrhythmogenesis in the murine heart
}

\author{
Sandeep S. Hothi • Iman S. Gurung • \\ Jennifer C. Heathcote $\cdot$ Yanmin Zhang • \\ Stephen W. Booth • Jeremy N. Skepper • \\ Andrew A. Grace $\cdot$ Christopher L.-H. Huang
}

Received: 9 December 2007 /Revised: 3 March 2008/Accepted: 23 March 2008 / Published online: 4 July 2008

(C) The Author(s) 2008

\begin{abstract}
The recently described exchange protein directly activated by cAMP (Epac) has been implicated in distinct protein kinase A-independent cellular signalling pathways. We investigated the role of Epac activation in adrenergically mediated ventricular arrhythmogenesis. In contrast to observations in control conditions $(n=20)$, monophasic action potentials recorded in 2 of 10 intrinsically beating and 5 of 20 extrinsically paced Langendorff-perfused wildtype murine hearts perfused with the Epac activator 8pCPT-2'-O-Me-cAMP (8-CPT, $1 \mu \mathrm{M})$ showed spontaneous triggered activity. Three of 20 such extrinsically paced hearts showed spontaneous ventricular tachycardia (VT). Programmed electrical stimulation provoked VT in 10 of 20 similarly treated hearts $(P<0.001 ; n=20)$. However, there were no statistically significant accompanying changes $(P>$ $0.05)$ in left ventricular epicardial $(40.7 \pm 1.2$ versus $44.0 \pm$ $1.7 \mathrm{~ms} ; n=10)$ or endocardial action potential durations $\left(\mathrm{APD}_{90} ; 51.8 \pm 2.3\right.$ versus $\left.51.9 \pm 2.2 \mathrm{~ms} ; n=10\right)$, transmural $\left(\Delta \mathrm{APD}_{90}\right)(11.1 \pm 2.6$ versus $7.9 \pm 2.8 \mathrm{~ms} ; n=10)$ or apico-
\end{abstract}

S. S. Hothi $(\bowtie) \cdot J$. C. Heathcote $\cdot$ S. W. Booth · C. L.-H. Huang Physiological Laboratory, University of Cambridge,

Downing Street,

Cambridge CB2 3EG, UK

e-mail: ssh26@cam.ac.uk

I. S. Gurung $\cdot$ Y. Zhang · A. A. Grace

Section of Cardiovascular Biology, Department of Biochemistry, University of Cambridge,

Tennis Court Road,

Cambridge CB2 1QW, UK

J. N. Skepper

Multi-Imaging Centre, University of Cambridge,

Cambridge CB2 3DY, UK basal repolarisation gradients, ventricular effective refractory periods $(29.1 \pm 1.7$ versus $31.2 \pm 2.4 \mathrm{~ms}$ in control and 8-CPT-treated hearts, respectively; $n=10$ ) and $\mathrm{APD}_{90}$ restitution characteristics. Nevertheless, fluorescence imaging of cytosolic $\mathrm{Ca}^{2+}$ levels demonstrated abnormal $\mathrm{Ca}^{2+}$ homeostasis in paced and resting isolated ventricular myocytes. Epac activation using isoproterenol in the presence of $\mathrm{H}-89$ was also arrhythmogenic and similarly altered cellular $\mathrm{Ca}^{2+}$ homeostasis. Epac-dependent effects were reduced by $\mathrm{Ca}^{2+} /$ calmodulin-dependent protein kinase II (CaMKII) inhibition with $1 \mu \mathrm{M} \mathrm{KN}-93$. These findings associate VT in an intact cardiac preparation with altered cellular $\mathrm{Ca}^{2+}$ homeostasis and Epac activation for the first time, in the absence of altered repolarisation gradients previously implicated in reentrant arrhythmias through a mechanism dependent on CaMKII activity.

Keywords Epac cAMP. Calcium · Ventricular arrhythmia . Ryanodine receptor CaMKII

\section{Introduction}

The second messenger cyclic adenosine monophosphate (cAMP) is involved in the regulation of major physiological processes in a wide range of cell types. For example, regulation of cardiac ventricular physiology by cAMP has long been viewed in terms of classical, protein kinase A (PKA)-dependent pathways in which stimulation of $\beta$ adrenoreceptors (BAR) activates the $G$ protein $G_{s}$ and thence adenylate cyclase thereby elevating cytosolic [cAMP]. The resulting PKA activation results in phosphorylation of multiple targets involved in excitation-contraction 
coupling, including L-type $\mathrm{Ca}^{2+}$ channels (LTCCs), phospholamban and the sarcoplasmic reticular (SR) cardiac ryanodine receptor- $\mathrm{Ca}^{2+}$ release channel RyR2. The latter releases the intracellularly stored $\mathrm{Ca}^{2+}$ in response to the initial LTCC-mediated $\mathrm{Ca}^{2+}$ influx that leads to contractile activation. This classical pathway is thought to lead to the inotropic, chronotropic and lusitropic effects of cAMP signalling [7].

An abnormally increased activation of this classical pathway has been implicated in hypotheses for ventricular arrhythmogenesis in both cardiac failure (HF) [58] and the inherited arrhythmia disorder catecholaminergic polymorphic ventricular tachycardia (CPVT) [59], conditions predisposing to sudden cardiac death (SCD) [31, 54]. Of these conditions, HF has been described as involving chronically elevated BAR-mediated cellular signalling [57]. In contrast, CPVT, caused by mutations in the calcium-handling proteins, calsequestrin (CasQ) or RyR2 [31], is associated with acute VT, which may degenerate further into VF and SCD, on adrenergic stimulation [10]. The pathophysiology of both HF and CPVT has been described in terms of schemes suggesting that PKAmediated phosphorylation of serine 2809 (or 2808, depending on species) of the RyR2 dissociates calstabin (FKBP12.6) from the RyR2 increasing its open probability $\left(\mathrm{P}_{\mathrm{o}}\right)$ [57]. However, (1) the exact phosphorylatable RyR2 sites [57, 62], (2) their individual protein kinases involved whether they include PKA, calcium-calmodulin-dependent protein kinase II (CaMKII) or protein kinase G (PKG) [8], and (3) the functional roles of such phosphorylation, are debated [8]. Finally, (4) some groups have not shown an association between PKA-induced phosphorylation of the RyR2 and a consequent FKBP12.6 dissociation [61].

Furthermore, discovery of the cAMP-dependent, exchange protein directly activated by $c$ AMP (Epac) $[16,26]$ has raised the possibility of alternative, PKA-independent, cAMP-dependent mechanisms of action in catecholaminergic BAR signalling. The Epac1 isoform is highly expressed in the heart as part of the macromolecular signalling complex regulating the RyR2, consisting of Epac, the muscle-specific A-kinase anchoring protein (mAKAP), PKA, and RyR2, and it has been suggested that there may be a functional coupling between the RyR and Epac [18, 22]. Epac activation by agents such as the specific activator 8-4-(chlorophenylthio)-2'-O-methyladenosine-3'-5'-monophosphate $(8-\mathrm{CPT})$ both opens $\mathrm{Ca}^{2+}$-sensitive big $\mathrm{K}^{+}$ channels and increases $\mathrm{Ca}^{2+}$ mobilisation in cerebellar neurones and stimulates $\mathrm{Ca}^{2+}$-induced $\mathrm{Ca}^{2+}$ release (CICR) in pancreatic $\beta$-cells confirming a role for Epac in $\mathrm{Ca}^{2+}$ handling (reviewed by Bos [9]). 8-CPT at low concentrations has been shown to be highly specific in activating Epac by up to 300 -fold compared to activation of PKA making it useful for investigating cAMP-dependent PKA- independent processes [22, 25]. 8-CPT used in excess of $100 \mu \mathrm{M}$ can activate PKA but with poor efficacy, activating PKA at only $20-30 \%$ of full activity even at $1 \mathrm{mM} 8$-CPT [11]. In this study, we accordingly use $1 \mu \mathrm{M} 8$-CPT to activate Epac highly specifically. In cardiac cells, 8-CPT increases the frequency of spontaneous cytosolic $\mathrm{Ca}^{2+}$ transients in neonatal rat cardiac myocytes [32]. Similarly, 8-CPT increases the amplitude of electrically evoked $\mathrm{Ca}^{2+}$ transients in murine cardiac myocytes [34]. Finally, 8-CPT increases the frequency of $\mathrm{Ca}^{2+}$ sparks reflecting SR $\mathrm{Ca}^{2+}$ release in isolated rat ventricular myocytes [36].

In both HF and CPVT, it has been suggested that alterations in RyR2 function could augment diastolic SR $\mathrm{Ca}^{2+}$ release consequently increasing diastolic cytosolic $\left[\mathrm{Ca}^{2+}\right]$ potentially activating a transient inward current $\left(I_{\mathrm{ti}}\right)$ [6], driven by forward mode NCX sodium influx [21]. This causes premature sarcolemmal depolarisation and triggered activity that both causes systolic dysfunction and increases arrhythmic tendency [38].

We directly investigated the effect of Epac activation by 8-CPT on arrhythmogenic tendency, confirmed with a second method of Epac activation using isoproterenol plus $\mathrm{H}-89$, in an isolated perfused intact mouse heart model paced at physiological heart rates for the first time. Our use of the intact heart permits inclusion of factors that may modulate abnormalities observed at the single cell level when then considered at the whole organ level. Such factors include intercellular electrical coupling and the arrangement of myocytes, electrical conduction systems and spatial heterogeneities of electrical properties reflected in nonuniformities of ion channel expression [48] and spatial heterogeneities of repolarisation [51]. Use of a mouse model permitted comparison with previous studies investigating the role of PKA-dependent pathways [58, 59]. It also permitted testing for and excluding reentrant mechanisms previously demonstrated for LQTS-type genetically modified murine systems [52, 53]

Having established the effects of Epac activation in the whole heart by two independent methods, 8-CPT and isoproterenol plus $\mathrm{H}-89$, we then proceeded to investigate the effects of Epac activation at the cellular level and related these to abnormalities in cytosolic $\mathrm{Ca}^{2+}$ handling. We thus demonstrate, for the first time to our knowledge, the arrhythmogenic consequences of Epac activation in any whole heart preparation. In contrast to previous arrhythmogenic phenomena in murine models of LQTS [27, 45, 46, $51,53]$, these phenomena were observed in the absence of evidence for reentrant mechanisms within the left ventricular free wall. Thus, alterations in transmural gradients of repolarisation, apico-basal gradients of repolarisation and action potential duration (APD) restitution were all absent. Instead, such effects were associated with aberrations in $\mathrm{Ca}^{2+}$ handling at the level of the single myocyte. 


\section{Materials and methods}

Experimental animals

Mice of the 129 background were kept in an animal house facility at room temperature $\left(21 \pm 1^{\circ} \mathrm{C}\right)$, subject to a $12: 12 \mathrm{~h}$ light/dark cycle. Sterile rodent chow and drinking water were available at all times. Male and female mice aged 57 months were used for the experiments.

\section{Heart isolation}

Mice were killed by rapid cervical dislocation in accordance with Schedule 1 of the UK Animals (Scientific Procedures) Act 1986. The isolated heart was quickly excised and transferred to ice-cold bicarbonate-buffered Krebs-Henseleit solution (mM: $\mathrm{NaCl} 119, \mathrm{NaHCO}_{3} 25$, $\mathrm{KCl} 4, \mathrm{KH}_{2} \mathrm{PO}_{4} 1.2, \mathrm{MgCl}_{2} 1, \mathrm{CaCl}_{2} 1.8$, glucose 10 and sodium pyruvate 2 , $\mathrm{pH} 7.4$ ) bubbled with $95 \% \mathrm{O}_{2}-5 \% \mathrm{CO}_{2}$ [5]. A small section of aorta (3-4 mm) was identified and cannulated with a tailor-made 21-gauge cannula that had been prefilled with ice-cold buffer. The aorta was secured onto the cannula with a micro-aneurysm clip (Harvard Apparatus, UK). The heart was then rapidly transferred and fixed to the perfusion system. The perfusate was passed through 200 and $5 \mu \mathrm{m}$ filters, and then warmed to $37^{\circ} \mathrm{C}$ by a water jacket and circulator. Perfusion was commenced in a retrograde manner through the aorta at $2-2.5 \mathrm{ml} / \mathrm{min}$ by a peristaltic pump (Watson-Marlow Bredel pumps model 505S, Falmouth, Cornwall, UK). In this way, the heart was perfused by the Krebs-Henseleit solution passing through the aorta, into the coronary ostia, and then into the coronary arteries, draining into the right atrium. After the initiation of perfusion, hearts regained a pink colour and spontaneous rhythmic contractions. After cannulation and the start of perfusion, approximately $10 \%$ of hearts were discarded due to ischaemia secondary to regional hypo-perfusion.

\section{Perfused heart electrophysiology}

Extrinsic stimulation was performed using paired platinum electrodes (1 $\mathrm{mm}$ interpole distance) gently positioned at the basal right ventricular epicardium. After initiation of perfusion, hearts were paced at $8 \mathrm{~Hz}$, using square wave pulses $2 \mathrm{~ms}$ in duration, with a stimulation voltage set to three times the diastolic threshold (Grass S48 Stimulator, Grass-Telefactor, Slough, UK) allowing direct comparison with previous murine studies of arrhythmogenesis [27].

Monophasic action potential (MAP) recordings were made from the basal left ventricular epicardium using a MAP electrode (Linton Instruments, Harvard Apparatus). Endocardial MAPs were recorded with a custom-made MAP electrode, composed from two strands of $0.25 \mathrm{~mm}$
Teflon-coated silver wire (99.99\% purity; Advent Research Materials, UK). The tips of the endocardial MAP electrode had previously been galvanically chlorided to eliminate DC offset. The electrode was introduced through a small access window made in the interventricular septum and then positioned on the lateral aspect of the left ventricular cavity, in opposition to the endocardial surface.

MAPs were pre-amplified using a NL100AK head stage, amplified with a NL 104A amplifier and band pass filtered between $0.5 \mathrm{~Hz}$ and $1 \mathrm{kHz}$ using a NL125/6 filter (Neurolog, Hertfordshire, UK) and then digitised (1401plus MKII, Cambridge Electronic Design, Cambridge, UK) at $5 \mathrm{kHz}$. MAP waveforms were analysed using Spike2 software (Cambridge Electronic Design, UK).

Electrocardiograms (ECGs) were recorded from the surface of the heart using commercially available ECG electrodes (Harvard Apparatus, Kent, UK). ECGs were recorded, amplified and filtered $(0.1-100 \mathrm{~Hz})$, with the negative electrode posterior to the right atrium, and the positive electrode at the ventricular apex.

\section{Experimental protocol}

After initiation of perfusion, hearts were paced at $8 \mathrm{~Hz}$ for $10 \mathrm{~min}$. MAPs were then recorded at baseline. Programmed electrical stimulation (PES) was used to assess inducibility of ventricular arrhythmias [5]. The PES protocol used consisted of a cycle of $8 \mathrm{~S} 1$ stimuli at a frequency of $8 \mathrm{~Hz}$, followed by a single extrastimulus, S2, initially $125 \mathrm{~ms}$ after the eighth $\mathrm{S} 1$. The S1-S2 interval was progressively reduced by $1 \mathrm{~ms}$ with each cycle. A ventricular arrhythmia was defined as five or more consecutive premature ventricular waveforms [27]. 8-CPT perfusion was then begun, consisting of a $10 \mathrm{~min}$ delivery time to the heart, during which hearts were paced at $8 \mathrm{~Hz}$, followed by a further 10 min of perfusion to allow the hearts to reach a steady state before PES procedures and MAP acquisition for quantification of MAP durations. A second independent method of Epac activation employed isoproterenol in the presence of the PKA inhibitor H-89. In such experiments, hearts were initially perfused with $2 \mu \mathrm{M} \mathrm{H}-89$ for $30 \mathrm{~min}$, followed by $100 \mathrm{nM}$ isoproterenol in the continued presence of $\mathrm{H}-89$. In a separate study to investigate the effects of BCL on left ventricular epicardial $\mathrm{APD}_{90}$, hearts were paced with a dynamic pacing protocol [45]. This began with a series of 100 stimuli at a BCL of $190 \mathrm{~ms}$, with the $\mathrm{BCL}$ reduced by $5 \mathrm{~ms}$ every 100 stimuli, until reaching a BCL of $65 \mathrm{~ms}$.

Isolation of ventricular cardiac myocytes

Solutions used for myocyte isolation were based on a stock buffer (SB) consisting of (in $\mathrm{mM}$ ): $125 \mathrm{NaCl}, 4.75 \mathrm{KCl}, 1.2$ 
$\mathrm{MgSO}_{4}, 1.2 \mathrm{KH}_{2} \mathrm{PO}_{4}, 30$ HEPES, 10 glucose, 50 taurine. After isolation and cannulation, hearts were perfused retrogradely with a perfusion buffer (PB) consisting of SB with the addition of $\mathrm{CaCl}_{2}$ to a concentration of $0.75 \mathrm{mM}$

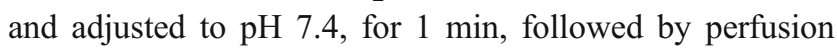
with a nitrilotriacetic acid (NTA)-based perfusion buffer consisting of SB, with NTA at $5 \mathrm{mM}$, adjusted to $\mathrm{pH} 6.95$. After 4 min, perfusion was switched to a digestion buffer containing SB to which had been added $1.0 \mathrm{mg} \mathrm{ml}^{-1}$ collagenase type-2 (Worthington, UK) and $1 \mathrm{mg} \mathrm{ml}^{-1}$ hyaluronidase (Sigma-Aldrich, Poole, UK). After 10$13 \mathrm{~min}$ digestion, the heart ventricular tissue was removed carefully from the left ventricle using fine forceps. Digestion was then terminated with $\mathrm{PB}$ containing $1 \mathrm{mg}$ $\mathrm{ml}^{-1}$ bovine serum album (Sigma-Aldrich, Poole, UK). Cells were dissociated by gentle trituration and centrifugation. $\mathrm{Ca}^{2+}$ was gradually reintroduced to the cells, resulting in a final concentration of $1.2 \mathrm{mM} \mathrm{Ca}^{2+}$. Cells were stored at room temperature and used for experiments within 4-6 h.

Measurement of cytosolic $\mathrm{Ca}^{2+}$ transients

Cells were transferred onto laminin-coated coverslips (Sigma-Aldrich, Poole, UK) and loaded with the acetoxymethyl (AM) ester of fluo-3 (Molecular Probes; Leiden, The Netherlands) by incubation with $5 \mu \mathrm{M}$ fluo-3 AM in perfusion buffer for $30 \mathrm{~min}$ in the dark. Perfusion buffer contained (in $\mathrm{mM}$ ): $125 \mathrm{NaCl}, 4.75 \mathrm{KCl}, 1.2 \mathrm{MgSO}_{4}, 1.2$ $\mathrm{KH}_{2} \mathrm{PO}_{4}, 30$ HEPES, 10 glucose, 50 taurine, $1.2 \mathrm{CaCl}_{2}$. Coverslips were then washed with perfusion buffer, and transferred to a custom-made chamber. This chamber was then mounted onto the stage of a Leica TCS SP5 confocal scanning laser microscopy system. A $\times 63$ water-immersion objective lens (numerical aperture 1.2; confocal aperture $600 \mu \mathrm{m}$; slice thickness $20.5 \mu \mathrm{m}$ ) was used on a Leica 6000 CS inverted microscope. Fluo-3 was excited using a $488 \mathrm{~nm}$ argon laser, and emission was collected between 505 and $550 \mathrm{~nm}$. Images were analysed using Leica AF software and data exported to Microsoft Excel for analysis. Fluorescence intensity $(F)$ was measured in regions of interest (ROIs) and normalised to the resting fluorescence intensity $\left(F_{0}\right)$. A total of 250 to 500 frames were sampled at a rate of $65 \mathrm{~ms} /$ frame, with each frame consisting of $256 \times$ 128 pixels. Recordings of fluorescence intensity were verified in the line scan mode, with the scan line parallel to the long axis of the cell and a recording rate of 1,400 Hz. Data acquired in the line scan mode were analysed with ImageJ (National Institutes of Health, Bethesda, MD, USA). In experiments involving extrinsic stimulation, cells were stimulated through two field electrodes, with pulses of $2 \mathrm{~ms}$ duration, at $0.5 \mathrm{~Hz}$ and $5 \mathrm{~V}$ above the excitation threshold of 30-60 V. Perfusion solutions were changed as required. The effects of Epac activation were measured 1 to
3 min after activation as reported previously [36]. In experiments involving KN-93 or H-89, cells were inhibited for 20 and $30 \mathrm{~min}$, respectively, before recordings were made. During subsequent pharmacological co-treatment, recordings were made within 1 to $3 \mathrm{~min}$. Experiments were conducted at room temperature $\left(22-24^{\circ} \mathrm{C}\right)$.

Pharmacological agents

8-pCPT-2'-O-Me-cAMP (BIOLOG Life Science Institute, Bremen, Germany) was dissolved in doubly distilled water to make a $1-\mathrm{mM}$ stock solution and stored at $-20^{\circ} \mathrm{C}$. Final drug concentrations were obtained by dilution with KrebsHenseleit buffer solution. 8-CPT was used at a final dose of $1 \mu \mathrm{M}$ (see "Introduction" section), at which it is highly specific for Epac over PKA [19], to minimise potential nonspecific effects and to increase the physiological relevance of consequent Epac activation. Furthermore, this dose is equal to that used in previous reports demonstrating increased phosphorylation of RyR2 [36] and alterations of $\mathrm{Ca}^{2+}$ handling in rat cardiomyocytes [32]. Isoproterenol (Sigma-Aldrich, Poole, UK) was dissolved in doubly distilled water to make a $10-\mathrm{mM}$ stock solution and stored at $-20^{\circ} \mathrm{C}$ and was used at a final concentration of $100 \mathrm{nM}$ [5]. KN-93 (Tocris Bioscience, Bristol, UK) was dissolved in dimethyl sulfoxide to $10 \mathrm{mM}$ stock and was used at a final concentration of $1 \mathrm{mM}$ [55]. H-89 (Sigma-Aldrich, Poole, UK) was dissolved in doubly distilled water to give a 2-mM stock and was used at a final concentration of $2 \mu \mathrm{M}$ [30].

\section{Statistical analysis}

Results were expressed as means \pm SEM, and different experimental groups were compared using analysis of variance (SPSS software) and Student's unpaired $t$ test as appropriate, with $P$ values less than 0.05 considered significant. Categorical data were compared with Fisher's exact test (one-tailed), with $P$ values less than 0.05 considered significant.

\section{Results}

After isolation and cannulation, hearts were perfused with Krebs-Henseleit solution. Extrinsic pacing was commenced from the basal right epicardial surface, and $10 \mathrm{~min}$ was allowed for the heart to reach steady-state. Programmed electrical stimulation (PES) was performed to assess arrhythmia inducibility in each pharmacological condition. After allowing $10 \mathrm{~min}$ of perfusion in the test condition, MAPs were recorded for $20 \mathrm{~min}$ under steady-state conditions of regular pacing. Where used, KN-93 and H89 perfused the heart for 20 and $30 \mathrm{~min}$, respectively, 
before experiments were commenced. During co-treatment of hearts with H-89 and isoproterenol, or KN-93 with 8CPT, we then allowed a further 10-min perfusion before PES was performed and MAPs were recorded. Closer analysis of the time evolution of any observed arrhythmogenesis used electrocardiographic electrodes. The results of these whole heart comparisons were, in turn, compared with fluo-3 fluorescence intensity used to follow $\mathrm{Ca}^{2+}$ transients obtained in regularly stimulated and resting ventricular myocytes before and after Epac activation.

Triggered activity occurs in both intrinsically beating and regularly paced hearts in the presence of 8-CPT

We initially observed unstimulated, intrinsically beating, hearts both under control conditions and after addition of 8CPT. In the absence of 8-CPT, such hearts never demonstrated triggered activity (Fig. 1a; $n=10$ ) in agreement with previous reports in isolated murine hearts under similarly bradycardic, control conditions [20, 52]. In contrast, during perfusion with 8-CPT, two out of ten such hearts developed triggered activity (Fig. 1b; $n=10$ ).

The incidence of such triggered activity was then systematically assessed in hearts regularly paced at a basic cycle length (BCL) of $125 \mathrm{~ms}$, close to physiological heart rates in the mouse [35]. Control hearts demonstrated consistently stable heart rates, with each monophasic action potential (MAP) closely following the preceding extrinsic stimulus, with no evidence of repolarisation abnormalities over 20 min sampling periods (Fig. 2a).

In contrast, in the presence of 8-CPT, 5 out of 20 hearts additionally demonstrated triggered activity occurring at irregular times during or after the recovery phase of some of the regularly occurring MAPs. This suggests a significant arrhythmogenic effect $(P<0.05$, Fisher's exact test; $n=$ 20 and 20, control and 8-CPT-treated hearts, respectively). Such triggered activity consisted of ectopic MAP waveforms occurring late in the recovery phase of the evoked MAPs or even after their full repolarisation, in agreement with the timing of either early afterdepolarisations (EADs) [27] or delayed afterdepolarisations (DADs) [23] described on previous occasions (Fig. 2b).

Spontaneous ventricular arrhythmia occurs in regularly paced hearts in the presence of 8-CPT

Such triggered activity further led to the initiation of episodes of spontaneous VT defined as five or more closely coupled action potentials [27] in 3 out of 20 hearts. Such episodes occurred in three out of the five hearts that showed triggered activity. Spontaneous VT was never observed in control hearts during steady pacing $(n=20)$. Thus, in hearts demonstrating triggered activity during 8-CPT treatment, a

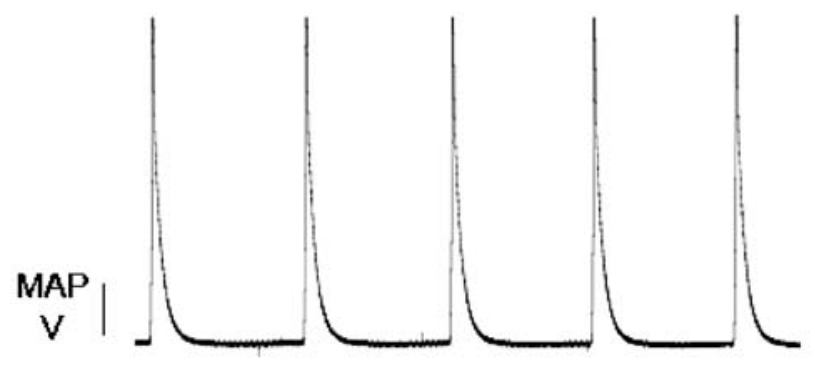

$500 \mathrm{~ms}$

$b$

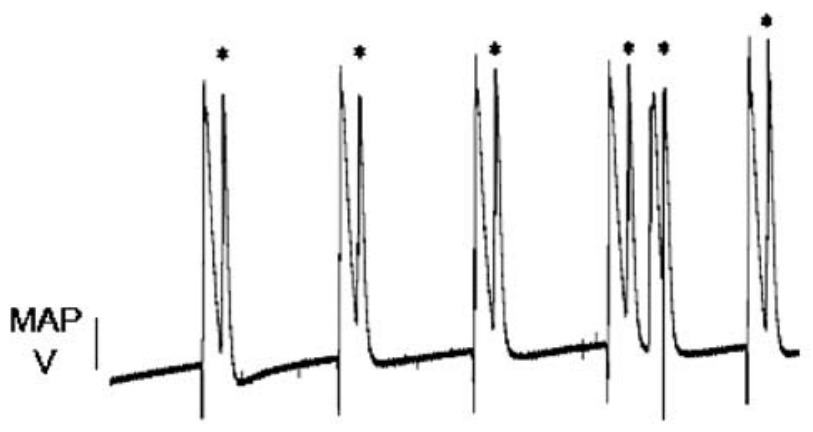

$500 \mathrm{~ms}$

$C$

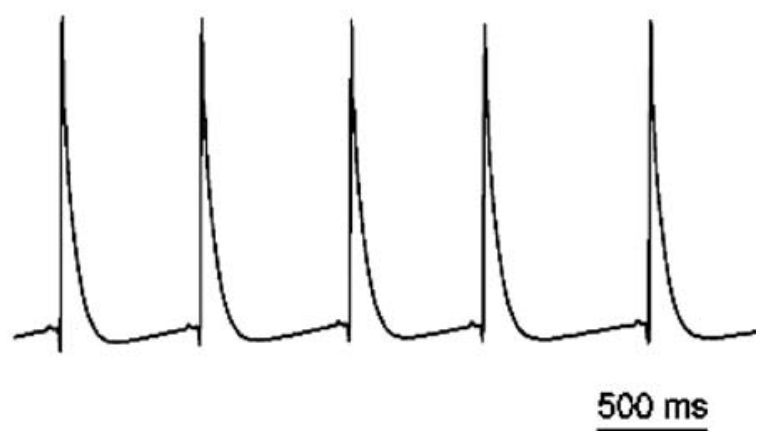

Fig. 1 Monophasic action potential (MAP) recordings from intrinsically beating hearts showed no triggered activity in control conditions (a), whereas two out of ten hearts developed triggered activity $(*)$ during perfusion with 8 -CPT (b). This was prevented by pretreatment with $\mathrm{KN}-93$ in seven out of seven hearts (c)

there was a significant tendency to spontaneous VT $(P<$ 0.05 , Fisher's exact test; $n=5$ and 20, 8 -CPT-treated and control hearts, respectively).

Figure 3 shows the evolution of such a typical arrhythmia after such ectopic activity in the presence of 8-CPT measured by electrocardiographic (ECG) analysis. These findings are in agreement with the corresponding evolution of human VF in that they can involve a sequence of different waveforms preceding the onset of VF [60]. Figure 3a demonstrates a spontaneous ectopic beat that was closely interrupted by a 
a

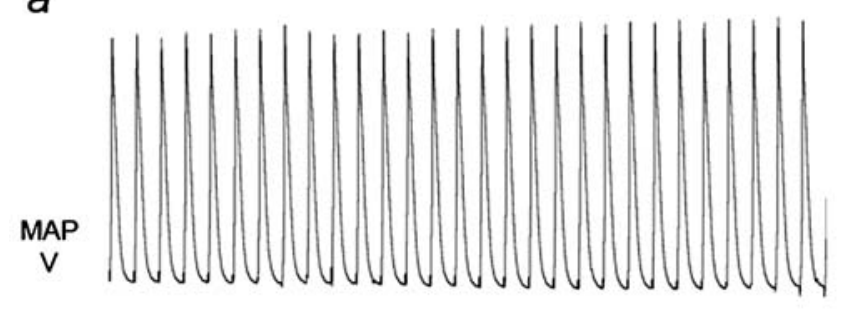

stimuli $++\mathrm{H}_{+}+\mathrm{H}_{+}+\mathrm{H}_{+}+\mathrm{H}_{+}+\mathrm{H}_{+}+\mathrm{H}_{+}+\mathrm{H}_{+}+\mathrm{H}$

$b$

$500 \mathrm{~ms}$
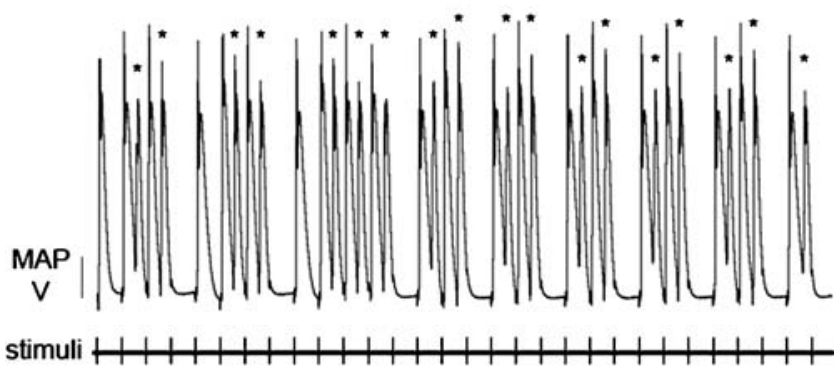

$500 \mathrm{~ms}$

$C$

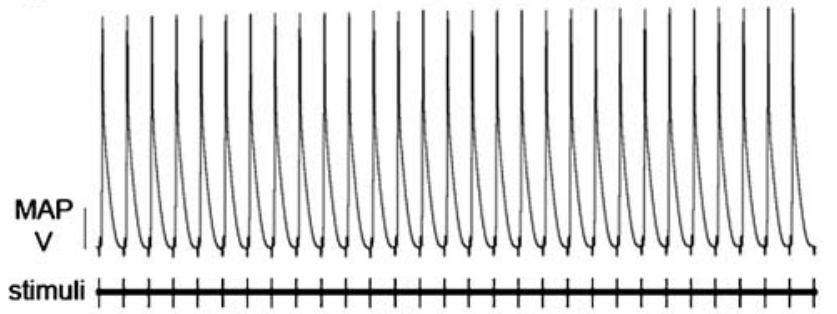

$500 \mathrm{~ms}$

Fig. 2 Monophasic action potential (MAP) recordings from extrinsically paced hearts in control conditions showing a typical regular rhythm with each MAP directly after its preceding extrinsic stimulus (a) then demonstrating triggered beats $\left(^{*}\right)$ during perfusion with $1 \mu \mathrm{M}$ 8-CPT in 5 out of 20 hearts (b). This was prevented by KN-93 pretreatment in seven out of seven hearts $(\mathbf{c})$

succeeding pacing spike that led onto the development of a sustained ventricular arrhythmia in an event resembling the clinical R-on-T phenomenon [43]. Figure 3b illustrates the subsequent monomorphic ECG waveform that then developed. However, this eventually evolved into a bidirectional VT (Fig. 3c), in agreement with clinical reports describing arrhythmogenesis in catecholaminergic polymorphic ventricular tachycardia (CPVT) similarly associated with alterations in $\mathrm{Ca}^{2+}$ homeostasis [31] and with an arrhythmogenic model with an underlying abnormality of $\mathrm{Ca}^{2+}$ homeostasis and a triggered as opposed to reentrant mechanisms of VT [10]. Finally, Fig. 3d demonstrates the final degeneration into ventricular fibrillation (VF; within $80.6 \mathrm{~s}$ of initiation of the arrhythmia). Such monomorphic VT, bidirectional VT and ventricular fibrillation were never observed in control conditions $(n=20)$.
Programmed electrical stimulation induces ventricular tachycardia in hearts following Epac activation

After the identification of these arrhythmogenic phenomena in regularly paced hearts perfused with 8-CPT, programmed electrical stimulation (PES) was used to systematically assess arrhythmogenic tendency in response to provoked extrasystolic stimulation at progressively closer intervals

a

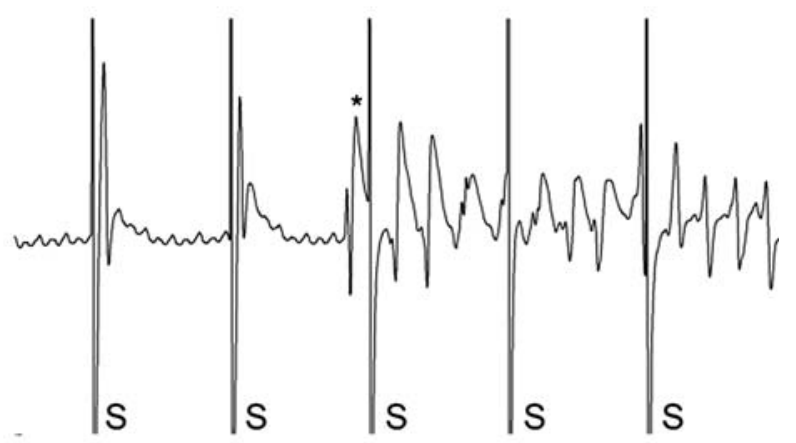

$b$

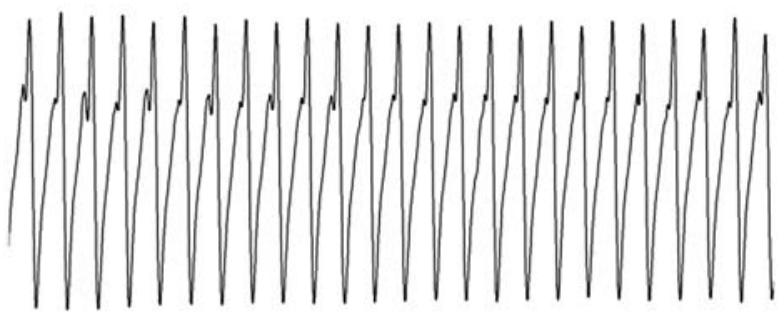

C

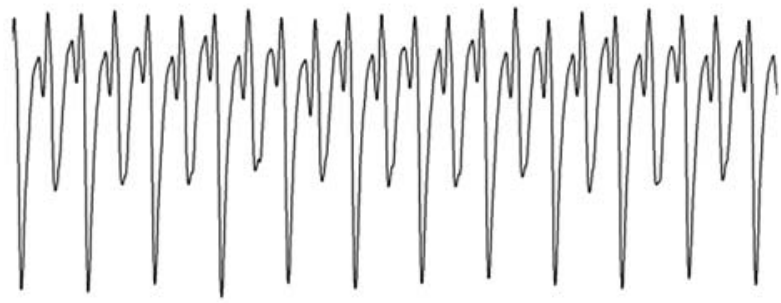

$d$

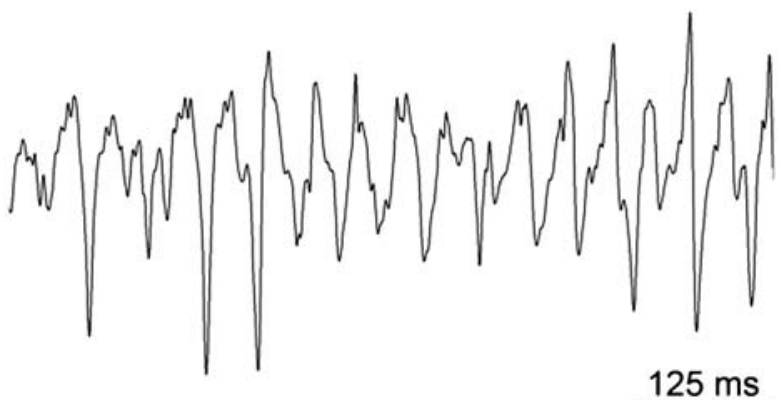

Fig. 3 The range of ECG waveforms during steady-state pacing (S indicates extrinsic pacing artefacts) after introduction of 8-CPT with ventricular tachycardia (VT) developing spontaneously after a triggered beat $(* ; a)$, changing successively into a self-sustaining monomorphic VT (b) and bidirectional VT (c), and finally degenerating into ventricular fibrillation (d). b-d are shown at twice the vertical magnification of (a) 
from the pacing stimuli, in isolated wild-type hearts perfused in control conditions using Krebs-Henseleit solution and then again during perfusion with $1 \mu \mathrm{M} 8$ CPT. Such PES techniques were adapted from clinical diagnostic techniques used to assess clinical arrhythmogenic tendency $[27,35,47]$. In control conditions, PES consistently failed to induce VT in all of 20 hearts (Fig. 4a). However, in the same 20 hearts then perfused with $1 \mu \mathrm{M} 8$ CPT, 10 out of 20 hearts developed VT after provocation using PES (Fig. $4 \mathrm{~b} ; n=20$ ). These findings demonstrate a significant arrhythmogenic effect of 8 -CPT $(P<0.001$; Fisher's exact test).

We then confirmed the arrhythmogenic effects of Epac by 8 -CPT through a more physiological activation by an increase in cytosolic [cAMP], increased by isoproterenol, whilst inhibiting PKA with H-89. All hearts initially perfused with the PKA inhibitor H-89 were refractory to PES $(n=8)$. However, in the same hearts then perfused with isoproterenol in the continued presence of H-89, VT was observed in five out of eight hearts, confirming a significant arrhythmogenic tendency following Epac activation by this second method of Epac activation $(P<0.05$ versus control).

Epac activation conserves action potential duration, transmural gradient of repolarisation and ventricular refractoriness

Previous work in both congenital and acquired LQTS has attributed arrhythmogenic properties to reentrant mechanisms attributable to alterations in epicardial and endocardial $\mathrm{APD}_{90}$ given by the time from peak depolarisation to $90 \%$ repolarisation, the transmural gradient of repolarisation, $\triangle \mathrm{APD}_{90}$ given by the difference between endocardial and epicardial $\mathrm{APD}_{90}$, the ventricular effective refractory period (VERP) and the relationship between the VERP and $\mathrm{APD}_{90}$. In such models, reentrant excitation was associated with both repolarisation abnormalities serving as initiating factors for arrhythmogenesis, coupled with abnormal
Fig. 4 Representative traces of monophasic action potential (MAP) recordings from isolated Langendorff-perfused hearts during programmed electrical stimulation (PES) under control conditions (a) in which PES failed to induce ventricular tachycardia (VT) in ten out of ten hearts. During perfusion with 8-CPT, PES led to VT that was self-sustaining even after cessation of pacing stimuli in 10 out of 20 WT hearts $(P<0.001$; $n=10$ ) (b shows one of the five hearts perfused with 8-CPT that developed VT). CaMKII inhibition with KN-93 prevented 8CPT-induced VT in seven out of seven hearts (c)
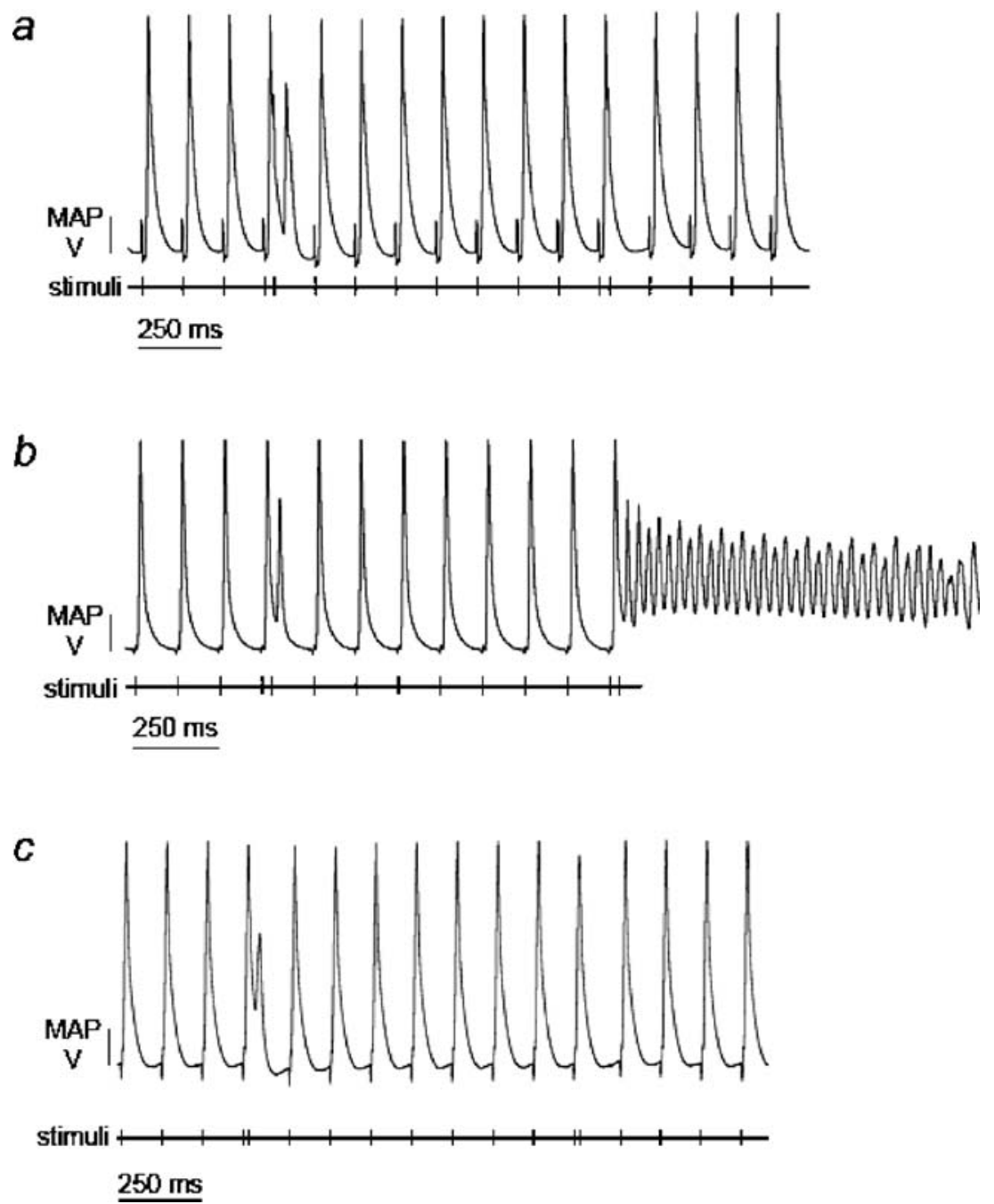
gradients of repolarisation that contribute to a substrate for reentrant circuits. However, the present findings suggested a contrasting mechanism.

Firstly, arrhythmogenesis in murine models of human LQT3 and LQT5, and of hypokalaemia has been attributed to prolonged epicardial $\mathrm{APD}_{90}$ nevertheless associated with either proportionately smaller or insignificant changes in endocardial $\mathrm{APD}_{90}[20,27,51,53]$. The present experiments were similarly performed using steady-state pacing at $8 \mathrm{~Hz}$ to determine epicardial and endocardial $\mathrm{APD}_{90}$. We similarly observed that there was no significant change in endocardial $\mathrm{APD}_{90}$ before and after application of 8-CPT $(51.8 \pm 2.2 \mathrm{~ms}$ versus $51.9 \pm 2.2 \mathrm{~ms}$, respectively, $(P>0.05$; $n=10$; Fig. 5)). We repeated $\mathrm{APD}_{90}$ measurements after Epac activation by the second method, using isoproterenol to stimulate cAMP production and H-89 to inhibit PKA. Initial experiments confirmed that H-89 alone did not alter $\mathrm{APD}_{90}$ in the epicardium $(42.5 \pm 2.8 \mathrm{~ms}, n=7)$ nor in the endocardium $(50.0 \pm 2.7 \mathrm{~ms}, n=4)$.

However, our present results contrasted with the earlier findings $[20,27,51,53]$ in that 8 -CPT exerted no significant effect on epicardial $\mathrm{APD}_{90}$. Thus, under control conditions, the mean epicardial $\mathrm{APD}_{90}$ was $40.4 \pm 1.2 \mathrm{~ms}$ ( $n=10$; Fig. 5); however, after perfusion with $1 \mu \mathrm{M} 8$-CPT, there was no significant change in mean epicardial $\mathrm{APD}_{90}$ at $44.0 \pm 1.7 \mathrm{~ms}(P>0.05 ; n=10)$. Epac activation by isoproterenol in the presence of H- 89 also did not alter epicardial $\mathrm{APD}_{90}$ from control values $(43.2 \pm 1.0, n=6)$. Such hearts also showed a conserved endocardial $\mathrm{APD}_{90}$, mean of $52.9 \pm 2.5 \mathrm{~ms}(n=6)$, not significantly different to control $(P>0.05)$.

Secondly, alterations in the consequent relationship between the epicardial and endocardial $\mathrm{APD}_{90}$ have been associated with arrhythmogenic substrates for reentrant excitation in those earlier models of LQTS [27, 51, 53]. We therefore sought to determine whether alterations in $\triangle \mathrm{APD}_{90}$ could be responsible for the arrhythmogenesis observed due to Epac activation. The latent period between stimulation and the peak of the evoked MAP did not significantly differ between the epicardium and endocardi- um, in control conditions and after Epac activation as observed on previous occasions in the murine heart (data not shown). The transmural gradient of repolarisation was therefore calculated as the difference between the endocardial and epicardial $\mathrm{APD}_{90}$, and represented by $\triangle \mathrm{APD}_{90}[27$, 53]. In control conditions, we observed $\triangle \mathrm{APD}_{90}$ to be $11.1 \pm$ $2.6 \mathrm{~ms}(n=10)$, consistent with the positive values recorded by previous investigators. We found no significant change after perfusion with 8 -CPT, with a $\triangle \mathrm{APD}_{90}$ equal to $7.9 \pm$ $2.8 \mathrm{~ms}(n=10$; Fig. 5). Using the second pharmacological method, isoproterenol plus $\mathrm{H}-89, \triangle \mathrm{APD}_{90}$ was $9.7 \pm 2.7 \mathrm{~ms}$ $(n=6)$, not different from the control $(P>0.05)$. Hence, in contrast to the previous models, an altered transmural gradient of repolarisation is not associated with arrhythmogenesis due to Epac activation by either 8-CPT or isoproterenol plus H-89.

Thirdly, the VERP is the determinant of the time period in which a myocardial region is capable of responding to a stimulus, whether appropriate and originating from the sinus node, or abnormal and due to ectopic or reentrant electrical activity, and is therefore an important determinant of local reexcitation. We assessed ventricular refractoriness in intact hearts using a decremental pacing protocol in control conditions versus Epac activation by either 8-CPT or isoproterenol plus H-89. The VERP was given by the shortest S1S2 interval that failed to elicit a MAP. After perfusion with either 8-CPT (Fig. 5), or isoproterenol plus H-89, there was no significant change in VERP $(29.1 \pm$ $1.7 \mathrm{~ms}, 31.2 \pm 2.4 \mathrm{~ms}$ and $31.3 \pm 3.0 \mathrm{~ms}$; control, 8 -CPT, and isoproterenol plus $\mathrm{H}-89$, respectively; $n=10, n=10$, and $n=$ 6 , respectively). Thus, relative changes in VERP alone are not determinants of arrhythmogenic tendency due to Epac activation.

Fourthly, it has additionally been suggested that the relationship between the epicardial $\mathrm{APD}_{90}$ and epicardial VERP is an important factor affecting arrhythmogenicity based on findings in a hypokalaemic model of acquired LQTS [44]. Thus, it has been proposed that there is a critical window for reexcitation by a premature stimulus given by the difference between the epicardial $\mathrm{APD}_{90}$ and
Fig. 5 Epicardial and endocardial $\mathrm{APD}_{90}, \triangle \mathrm{APD}_{90}$ and VERP in control conditions (clear bars; $n=10$ ), during perfusion with $1 \mu \mathrm{M}$ 8-CPT (black bars; $n=10$ ) and in hearts pretreated with $1 \mu \mathrm{M} \mathrm{KN}-93$ to inhibit CaMKII and co-perfused with 8-CPT (striped bars). All such parameters were not significantly altered from control values by 8 -CPT or KN-93 plus 8-CPT $(P>0.05)$

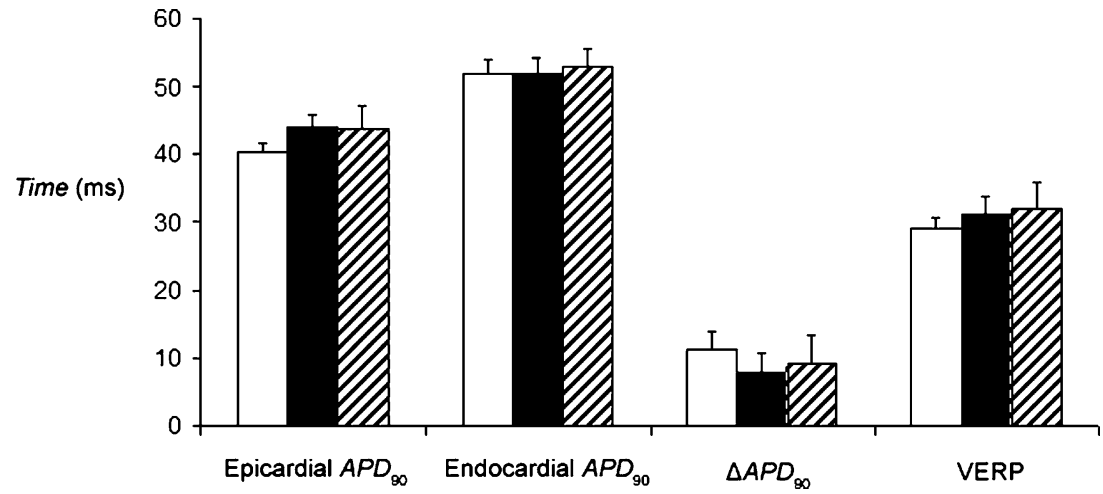


the epicardial VERP. Hence, relative changes in VERP and epicardial $\mathrm{APD}_{90}$, rather than the analysis of one such factor in isolation may be required in a rigorous assessment of the propensity to cardiac arrhythmogenesis. However, quantification of the critical window in both control and 8-CPTtreated hearts did not yield a significant difference $(11.1 \pm 2.1$ versus $12.8 \pm 3.0 \mathrm{~ms}$, control and 8 -CPT respectively; $n=10$ in both cases). A similar analysis for Epac activation by isoproterenol plus 8-CPT also showed a conservation of this critical window for reexcitation, $12.0 \pm 4.3$ versus $11.1 \pm$ $2.1 \mathrm{~ms}$, isoproterenol plus $\mathrm{H}-89$ and control respectively, $P>$ $0.05, n=6$ and 10). These findings are consistent with the preservation of both the epicardial $\mathrm{APD}_{90}$ and VERP by Epac activation, whilst also suggesting that neither changes in refractoriness nor changes in the critical window are determinants of arrhythmogenesis in this model.

Finally, in the absence of altered $\mathrm{APD}_{90}, \triangle \mathrm{APD}_{90}$ and VERP, we investigated the apico-basal gradient of repolarisation. In hearts perfused with control solution, the apical $\mathrm{APD}_{90}$ was $35.6 \pm 2.2(n=10)$, significantly shorter than the basal $\mathrm{APD}_{90}(40.2 \pm 1.3, n=10 ; P<0.05)$, consistent with previous reports [3]. The resulting apico-base gradient of repolarisation was $-5.4 \pm 2.5 \mathrm{~ms}$. Following Epac activation, by either 8 -CPT or isoproterenol and H-89, neither the apical $\mathrm{APD}_{90}$ nor the apico-basal gradient of repolarisation were significantly altered (Table 1).

Thus, these quantifications of the electrophysiological effects of Epac activation by two independent pharmacological methods on intact Langendorff preparations, performed for the first time, demonstrate both the initiation and maintenance of spontaneous arrhythmogenic phenomena in the face of normal epicardial and endocardial $\mathrm{APD}_{90}$, $\triangle \mathrm{APD}_{90}$, VERP and apico-basal gradient of repolarisation and therefore a preserved relationship between the $\mathrm{APD}_{90}$ and VERP. This sharply contrasted with changes observed in previous murine models for reentrant arrhythmogenesis, consistent with differing underlying arrhythmogenic mechanisms. These findings therefore argue for a mechanism of arrhythmia distinct to one of reentrant excitation within the left-ventricular free wall.

They also demonstrate the presence of repolarisation abnormalities without the prolonged epicardial $\mathrm{APD}_{90}$, further supporting previous results showing a lack of effect of Epac activation on the APD at the cellular level [36].
Furthermore, some of these occurred after recovery of the MAP to baseline. This is in contrast to the situation in which prolonged $\mathrm{APD}_{90}$ may serve as an initiator of EADs in models of LQTS by enhancing the ability for reactivation of the L-type $\mathrm{Ca}^{2+}$ channel [24]. Such findings would be compatible with recent suggestions of a scheme in which VT in a mouse model of CPVT is initiated and maintained by one or more ectopic foci [10].

The effect of stimulation rate on electrophysiological properties during Epac activation

Finally, we proceeded to investigate the effect of BCL on $\mathrm{APD}_{90}$ with a dynamic pacing protocol as used recently in isolated perfused murine hearts [45, 46], whilst MAPs were recorded from the left ventricular basal epicardium. Hearts were paced for 100 stimuli at a BCL of $190 \mathrm{~ms}$, with $5 \mathrm{~ms}$ decrements in the BCL every 100 stimuli until reaching the shortest BCL of $65 \mathrm{~ms}$. Firstly, we examined the effect of BCL on the measured $\mathrm{APD}_{90}$ over this range of stimulation rates. These results showed a general decrease in $\mathrm{APD}_{90}$ as BCL was decreased. There was a minor prolongation of $\mathrm{APD}_{90} \mathrm{~S}$ over the entire range of BCLs during 8-CPT perfusion, though there was no significant difference between control and 8-CPT-treated hearts. This is shown in Fig. 6a.

Secondly, we assessed beat-to-beat variations in $\mathrm{APD}_{90}$ over the entire range of BCLs studied. The magnitude of MAP alternans, a clinical predictor of arrhythmogenicity [42], was given by the difference between odd and even numbered MAPs [45]. We observed a general trend towards increasing alternans magnitude as BCL decreased, in both control and 8-CPT-treated hearts (Fig. 6b). Over the entire range of BCLs, 8-CPT-treated hearts showed a slightly larger alternans magnitude, especially at shorter BCLs, with three out of five 8-CPT-treated hearts having an alternans magnitude greater than $1 \mathrm{~ms}$ at BCLs of 70 and $65 \mathrm{~ms}$, compared to one out of five control hearts at a BCL of $70 \mathrm{~ms}$, and two out of five control hearts at $65 \mathrm{~ms}$. This difference did not reach statistical significance $(n=5$ for both control and 8-CPT-treated hearts).

Finally, the relationship of the $\mathrm{APD}_{90}$ to the diastolic interval (DI) has been used to study action potential duration restitution characteristics, and arrhythmogenic tendency has been associated with increases in the maximum gradient of

Table 1 Basal and apical $\mathrm{APD}_{90}$ and the resultant apico-basal gradient of repolarisation recorded from isolated hearts extrinsically paced at $8 \mathrm{~Hz}$

\begin{tabular}{lllll}
\hline Condition & Basal APD $90(\mathrm{~ms})$ & Apical APD $90(\mathrm{~ms})$ & Apex-base gradient (ms) & $P($ versus control) \\
\hline Control & $40.2 \pm 1.3(n=10)$ & $35.6 \pm 2.2(n=10)$ & $-5.4 \pm 2.5$ & \\
8 -CPT & $44.0 \pm 1.7(n=10)$ & $36.7 \pm 3.2(n=10)$ & $-7.4 \pm 3.7$ & NS \\
KN-93 + 8-CPT & $43.8 \pm 2.8(n=7)$ & $36.8 \pm 4.3(n=7)$ & $-7.1 \pm 3.9$ & NS \\
H-89+ isoproterenol & $43.2 \pm 1.0(n=6)$ & $37.4 \pm 4.1(n=6)$ & $-5.8 \pm 4.1$ & NS \\
\hline
\end{tabular}



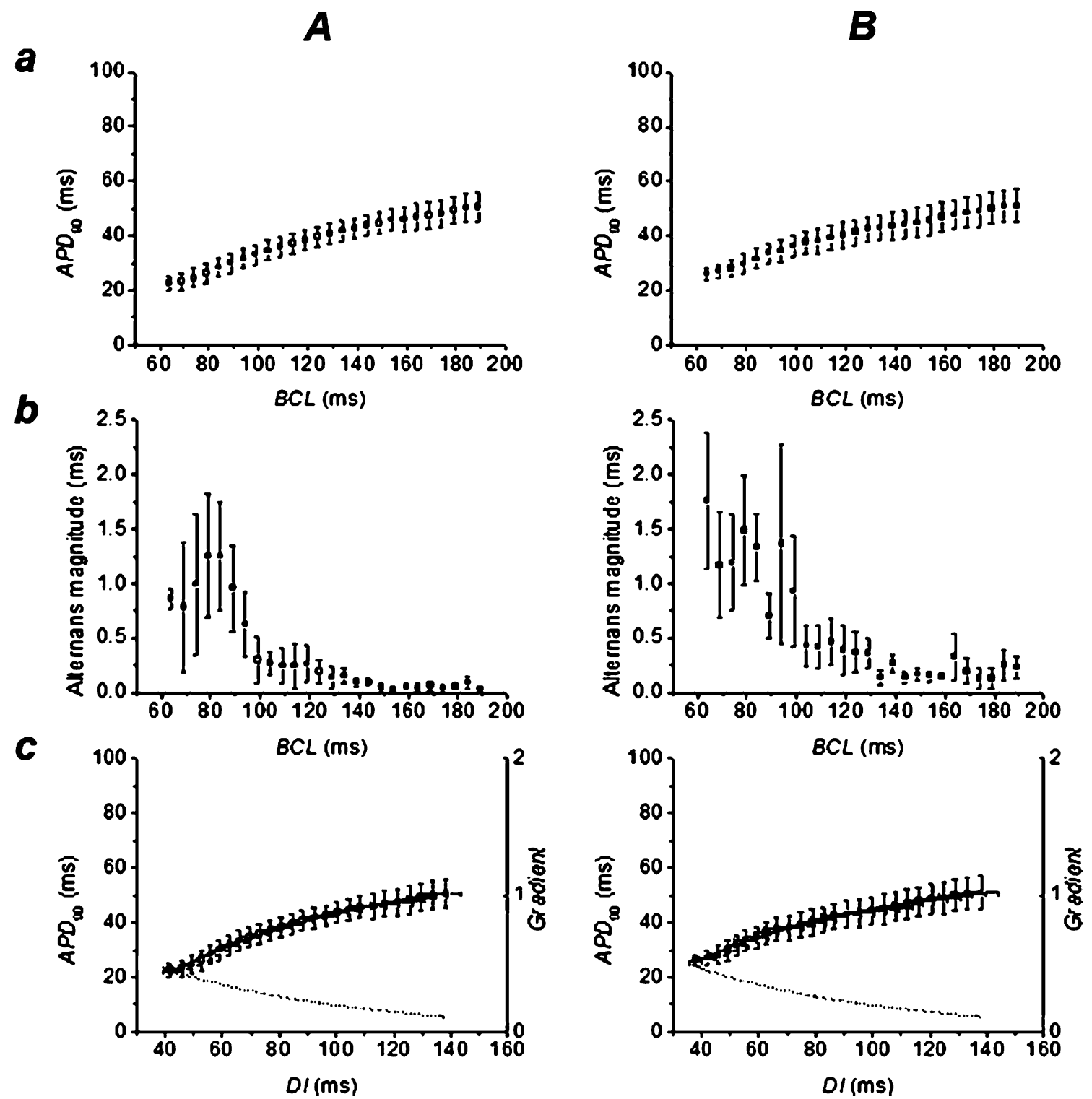

Fig. 6 Control hearts (A) and 8-CPT-perfused hearts (B) were investigated with a dynamic pacing protocol. $\mathrm{APD}_{90}$ decreased as BCL decreased (a) though it did not significantly differ between control and 8-CPT-treated hearts. Analysis of $\mathrm{APD}_{90}$ alternans (b) showed an increase in alternans magnitude as BCL decreased in both conditions. Restitution curves were obtained by plotting $\mathrm{APD}_{90}$ against the preceding DI (c) and data points were fitted with the function $y=y_{0}+A\left(1-e^{x / \tau}\right)$. The dashed line shows the gradient of

such curves. Such analyses have been extended to murine hearts and correlated with arrhythmogenic tendency in mouse models of human LQT3, Brugada syndrome and hypokalaemia [45, 46]. A similar analysis in the present study has been made by fitting the experimental data points with a monoexponential function $[45,46]$ of the form:

$y=y_{0}+A\left(1-e^{x / \tau}\right)$

where $y$ represents the $\mathrm{APD}_{90}$ and $x$ represents the DI. $A, \iota$ and $y_{0}$ are constants obtained by fitting the function to the the fitted function. In neither conditions did the gradient exceed unity over the range of experimental BCLs. Parameters used in curve fitting in control conditions: $y_{0}=-9.9 \pm 2.2 \mathrm{~ms}, A=70.3 \pm 1.0 \mathrm{~ms}, \tau=70.5 \pm$ $5.6 \mathrm{~ms}$. Corresponding parameters for hearts perfused with 8-CPT: $y_{0}=1.5 \pm 1.9 \mathrm{~ms}, A=56.9 \pm 0.8 \mathrm{~ms}, \tau=69.2 \pm 6.3 \mathrm{~ms}$. Critical diastolic interval $(\mathrm{CDI})$ for control $=-0.2 \mathrm{~ms}$, CDI for 8 -CPT perfused hearts $=$ $-13.6 \mathrm{~ms}$. Reduced $\chi^{2}=0.027$ and 0.025 , control and 8-CPT, respectively

experimental data points by a least squares method, using a Levenberg-Marquardt algorithm. The values of these constants and the reduced chi-squared values are given with the figure legends. The gradient of the fitted function is given by:

$\frac{\mathrm{d} y}{\mathrm{~d} x}=\frac{A}{\tau} e^{x / \tau}$

Analysis of the maximum gradient observed at the lowest experimental value of $x$ revealed that control hearts showed a 
maximal gradient of $0.55 \pm 0.03(n=5)$, and hearts treated with 8-CPT showed a maximal gradient of $0.47 \pm 0.03(n=5)$, not significantly different to control $(P>0.05$; Fig. 6c). Thus, restitution curves previously used to predict arrhythmogenicity in a range of murine models failed to predict arrhythmogenicity resulting from Epac activation. Previous studies had extended the restitution analysis to predict the critical DI (CDI), the DI at which the gradient would equal unity, based on the fitted function $[45,46]$. Testing this concept here reveals a CDI less than zero in both control and 8 -CPT-treated hearts, $-0.16 \pm 0.02 \mathrm{~ms}$ versus $-13.6 \pm 1.78 \mathrm{~ms}$, for control and 8-CPT-treated hearts, respectively $(n=5$ in both cases). In both cases, restitution analysis would not predict a gradient greater than one in any real as opposed to negative BCL. If anything, the CDI was increased with 8CPT. Thus, action potential duration restitution properties incorporating analysis of the maximum gradient observed and predicted CDI fail to correlate with VT due to Epac activation. This is in sharp contrast to murine studies of arrhythmia consequent to LQTS and Brugada syndrome [46].

Epac-mediated arrhythmogenesis is dependent on $\mathrm{Ca}^{2+} /$ calmodulin-dependent protein kinase II

Previous reports have suggested that $\mathrm{Ca}^{2+} /$ calmodulindependent protein kinase II (CaMKII) activity is necessary for Epac-mediated effects on $\mathrm{Ca}^{2+}$ handling in cardiac myocytes [36]. We accordingly investigated the dependence upon CaMKII of the arrhythmogenic features observed at the whole organ level after Epac activation. KN-93 was used to inhibit CaMKII at $1 \mu \mathrm{M}$ after a careful review of the literature. Thus KN-93 has been used at $1 \mu \mathrm{M}$ to inhibit CaMKII at the cellular [13, 36] and whole organ [55] levels. Hearts were pretreated with $\mathrm{KN}-93$ for $20 \mathrm{~min}$ before experiments were performed [2]. For experiments involving co-treatment with both 8-CPT and $\mathrm{KN}-93$, 8-CPT was perfused in the continued presence of $\mathrm{KN}-93$, and a further 10 min were allowed before PES was performed and MAP recordings were made. Initial studies revealed that $\mathrm{KN}-93$ alone did not alter the epicardial $\mathrm{APD}_{90}(44.3 \pm 3.3$, $n=7)$ nor endocardial $\mathrm{APD}_{90}(52.3 \pm 3.2 \mathrm{~ms}, n=4)$. Hearts first perfused with $\mathrm{KN}-93$ alone did not demonstrate triggered activity or spontaneous VT. Perfusion with 8CPT in the continued presence of KN-93 then also failed to show triggered activity and spontaneous VT (Fig. 1c). Thus, KN-93 exerted an anti-arrhythmic effect in spontaneously beating hearts.

Hearts paced regularly at $8 \mathrm{~Hz}$ in the presence of KN-93 alone also showed no evidence of triggered activity or spontaneous VT, similar to hearts perfused with control solution. After perfusion with both $\mathrm{KN}-93$ and 8-CPT in the same seven hearts, there were no arrhythmogenic phenomena of triggered activity or VT (Fig. 2c).
Stimulation of hearts by PES and treated with KN-93 alone failed to elicit VT in all hearts studied $(n=7)$. Perfusion of the same seven hearts with 8-CPT but in the continued presence of $\mathrm{KN}-93$ also failed to induce VT (Fig. 4c), in sharp contrast to hearts perfused with 8-CPT alone. Thus, KN-93 exerted a significant anti-arrhythmic effect $(P<0.05)$.

Such anti-arrhythmic actions of KN-93 occurred in the absence of alterations in epicardial and endocardial $\mathrm{APD}_{90}$. Thus, epicardial $\mathrm{APD}_{90}$ in the presence of KN-93 and 8CPT was $43.9 \pm 3.2 \mathrm{~ms}(n=7)$, and endocardial $\mathrm{APD}_{90}$ was $52.9 \pm 2.5 \mathrm{~ms}(n=7)$, not significantly different to controls or 8-CPT-treated hearts. Thus, $\triangle \mathrm{APD}_{90}$ was $9.1 \pm 4.1 \mathrm{~ms}$ $(n=7)$ versus $11.1 \pm 2.6 \mathrm{~ms}(n=10)$ in controls, which did not differ significantly. The VERP in hearts co-treated with $\mathrm{KN}-93$ and 8-CPT was $31.8 \pm 4.0 \mathrm{~ms}(n=7)$, and thus the critical window was $12.1 \pm 5.2 \mathrm{~ms}(n=7)$. In addition, the apico-basal gradient of repolarisation was not altered by KN-93 compared to control, 8-CPT or isoproterenol plus H89 ( $P>0.05$ in all such comparisons; Table 1). Therefore, CaMKII inhibition rescued Epac-mediated VT without alterations in epicardial or endocardial $\mathrm{APD}_{90}, \triangle \mathrm{APD}_{90}$, apico-basal gradient of repolarisation, VERP or the critical window.

Epac-mediated arrhythmogenesis correlates with altered cytosolic $\mathrm{Ca}^{2+}$ transients in regularly paced ventricular myocytes

Finally, having observed that Epac activation is arrhythmogenic at the level of the whole heart, yet with a conservation of endocardial and epicardial $\mathrm{APD}_{90}$, $\triangle \mathrm{APD}_{90}$ and refractory periods, we therefore sought to determine whether abnormalities in $\mathrm{Ca}^{2+}$ handling at the level of the single ventricular myocyte may be implicated instead. Thus, abnormalities in cytosolic $\mathrm{Ca}^{2+}$ handling in isolated myocytes have been associated with arrhythmogenesis at the level of the whole heart [4]. Furthermore, Epac activation by 8-CPT has been associated with abnormalities in $\mathrm{Ca}^{2+}$ handling in a wide number of cell types, including rat ventricular myocytes [36].

Firstly, extrinsically paced myocytes perfused in control solution demonstrated regular $\mathrm{Ca}^{2+}$ transients, in synchrony with the pacing stimuli $(n=27)$. Such cells showed characteristic, regularly timed increases in $F / F_{0}$ (Fig. 7a). In sharp contrast, after perfusion with 8-CPT, 8 out of 16 paced cells demonstrated additional $\mathrm{Ca}^{2+}$ transients which occurred at variable times out of synchrony with the extrinsic pacing stimuli. Such differences in the observed $\mathrm{Ca}^{2+}$ transients therefore reveal a significant effect of 8CPT on diastolic $\mathrm{Ca}^{2+}$ release $(P<0.001$, Fisher's exact test). Thus, the fluorescence signals demonstrated irregularly timed rises in $F / F_{0}$ in such cells (Fig. $7 \mathrm{~b}, \mathrm{c}$ ). The mean 

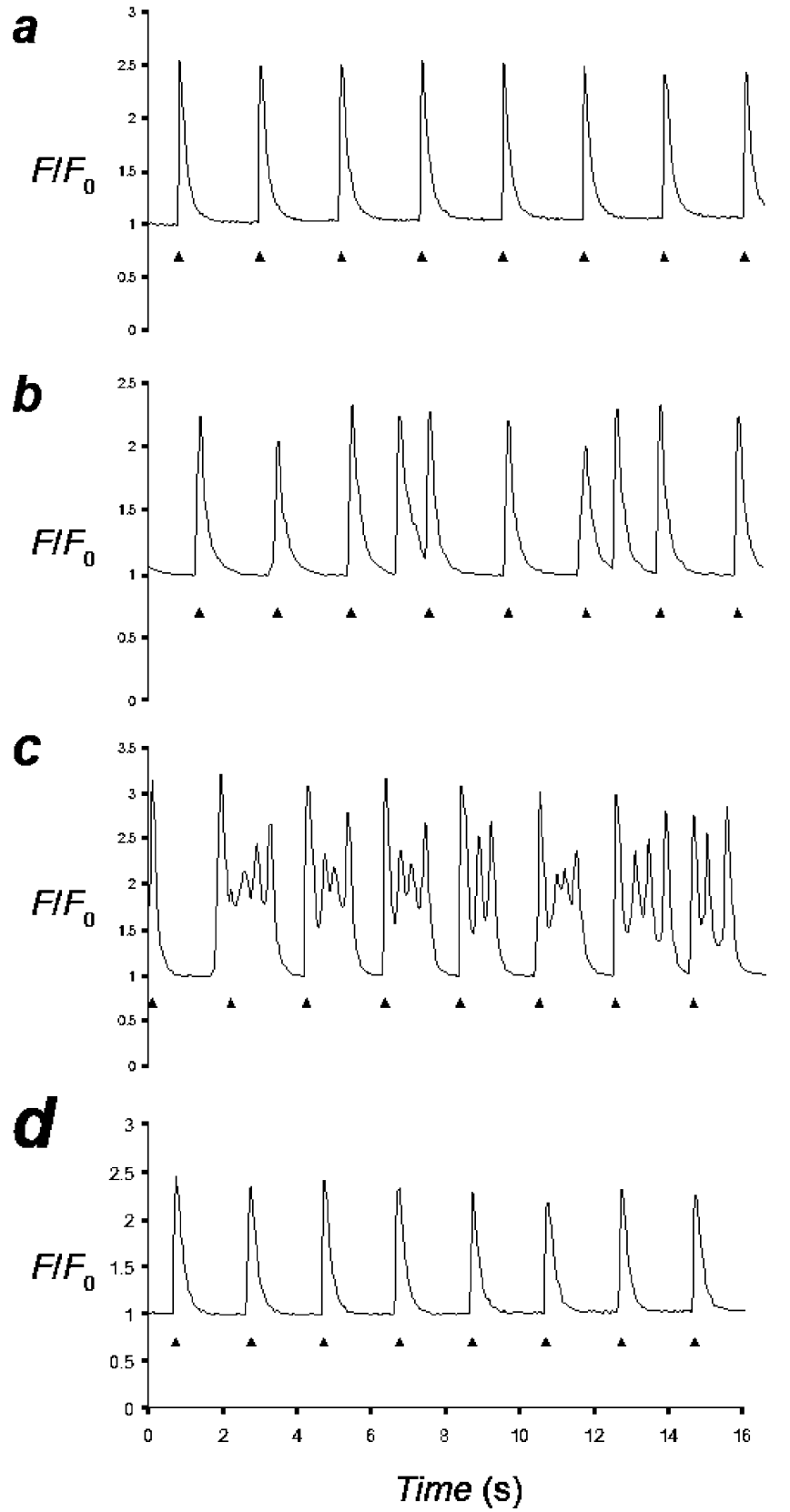

Fig. $7 \mathrm{Ca}^{2+}$ signals observed in regularly stimulated ventricular myocytes in control conditions showed a regular series of transients directly after the extrinsic stimuli (a) in 22 out of 22 cells. In contrast, $\mathrm{Ca}^{2+}$ signals observed during treatment with 8-CPT (b and $\mathbf{c}$ are recordings from two different cells) showed ectopic $\mathrm{Ca}^{2+}$ transients that were irregular, both in time and in peak magnitude, in 8 out of 16 cells $(P<0.01)$. KN-93 significantly prevented the occurrence of 8 CPT-induced ectopic $\mathrm{Ca}^{2+}$ transients in all cells $(\mathbf{d} ; P<0.01$ versus 8 CPT, $n=15)$. Triangles indicate extrinsic pacing stimuli

peak $F / F_{0}$ was not significantly altered by 8 -CPT $(3.07 \pm$ 0.79 vs. $2.58 \pm 0.49, n=15$ for 8 -CPT treated cells, $n=27$ for control cells). These results were confirmed in the line scan mode in a further set of cells studied at the higher sampling rate, where the mean maximum $F / F_{0}$ was $3.13 \pm 0.23$ in 8 -
CPT-treated cells $(n=16)$ and $2.94 \pm 0.23$ in the absence of 8-CPT $(n=22)$, without a statistically significant difference. We then tested Epac activation by the second method of activation. $\mathrm{H}-89$ alone caused no ectopic $\mathrm{Ca}^{2+}$ transients $(n=14)$. Isoproterenol plus $\mathrm{H}-89$, produced ectopic $\mathrm{Ca}^{2+}$ transients, in 4 out of 17 cells, statistically similar to the effects of 8-CPT. These ectopic $\mathrm{Ca}^{2+}$ transients induced by isoproterenol plus H-89 occurred in the absence of altered mean peak $F / F_{0}$ in both the frame scan mode (Table 2) and confirmed with the line scan mode (Table 3 ). These results are consistent with the hypothesis that such abnormal cytosolic $\mathrm{Ca}^{2+}$ transients are arrhythmogenic predominantly through abnormalities of diastolic as opposed to systolic $\mathrm{Ca}^{2+}$ release.

Epac-mediated arrhythmogenesis correlates with spontaneous cytosolic $\mathrm{Ca}^{2+}$ waves in resting ventricular myocytes

Secondly, we proceeded to investigate $\mathrm{Ca}^{2+}$ transients in resting as opposed to stimulated isolated ventricular myocytes. In control conditions, such myocytes never demonstrated any $\mathrm{Ca}^{2+}$ transients $(n=20)$. In contrast, after introduction of 8-CPT, there were significant alterations in resting $\mathrm{Ca}^{2+}$ homeostasis as a consequence of the resulting Epac activation. Thus, 9 out of 16 cells demonstrated spontaneous $\mathrm{Ca}^{2+}$ transients $(P<0.001$, Fisher's exact test; $n=20$ and 16 , control and 8-CPT-treated myocytes, respectively), which took the form of $\mathrm{Ca}^{2+}$ waves in 9 out of 16 cells reflected in a fluorescent region that propagated either uni- or bidirectionally along the long axis of the cell. Activation of Epac by the second method using isoproterenol plus $\mathrm{H}-89$ caused ectopic $\mathrm{Ca}^{2+}$ signals in 10 out of 18 cells, compared to none of 23 cells treated with H-89 alone, a significant effect $(P<0.001)$. These two methods of Epac activation similarly caused ectopic $\mathrm{Ca}^{2+}$ transients in resting cells.

Inspection of fluorescence intensity changes in spatially successive frames acquired during the course of a typical

Table 2 Mean peak $F / F_{0}$ signals recorded in paced myocytes in the frame scan mode

\begin{tabular}{llll}
\hline Condition & $n$ & $F / F_{0}$ & $P$ (versus control) \\
\hline Control & 22 & $2.54 \pm 0.54$ & \\
8-CPT & 15 & $3.07 \pm 0.64$ & NS \\
KN-93 & 14 & $2.21 \pm 0.59$ & NS \\
8-CPT + KN-93 & 15 & $2.39 \pm 0.62$ & NS \\
Isoproterenol & 16 & $3.57 \pm 0.89$ & $<0.01$ \\
H-89 & 11 & $2.20 \pm 0.66$ & NS \\
Isoproterenol + H-89 & 15 & $2.85 \pm 0.69$ & NS \\
\hline
\end{tabular}


Table 3 Mean peak $F / F_{0}$ signals recorded in paced myocytes in the line scan mode

\begin{tabular}{llll}
\hline Condition & $n$ & $F / F_{0}$ & $P$ (versus control) \\
\hline Control & 17 & $2.76 \pm 0.25$ & \\
8-CPT & 16 & $3.13 \pm 0.23$ & $\mathrm{NS}$ \\
KN-93 & 18 & $3.03 \pm 0.21$ & $\mathrm{NS}$ \\
8-CPT + KN-93 & 24 & $2.66 \pm 0.13$ & $\mathrm{NS}$ \\
Isoproterenol & 10 & $3.74 \pm 0.18$ & $<0.01$ \\
H-89 & 13 & $2.68 \pm 0.17$ & $\mathrm{NS}$ \\
Isoproterenol + H-89 & 18 & $3.07 \pm 0.23$ & $\mathrm{NS}$ \\
\hline
\end{tabular}

a
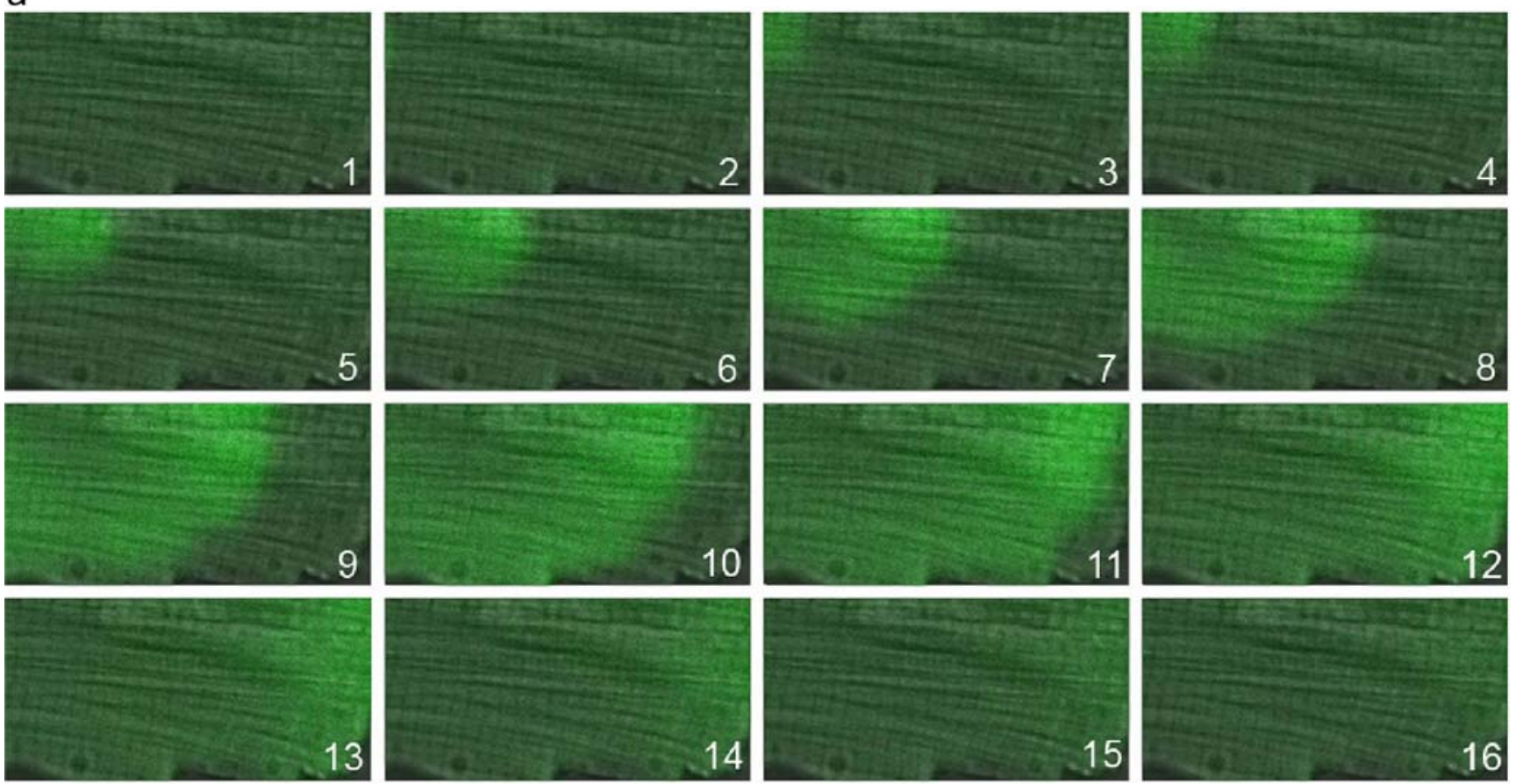

C

$b$
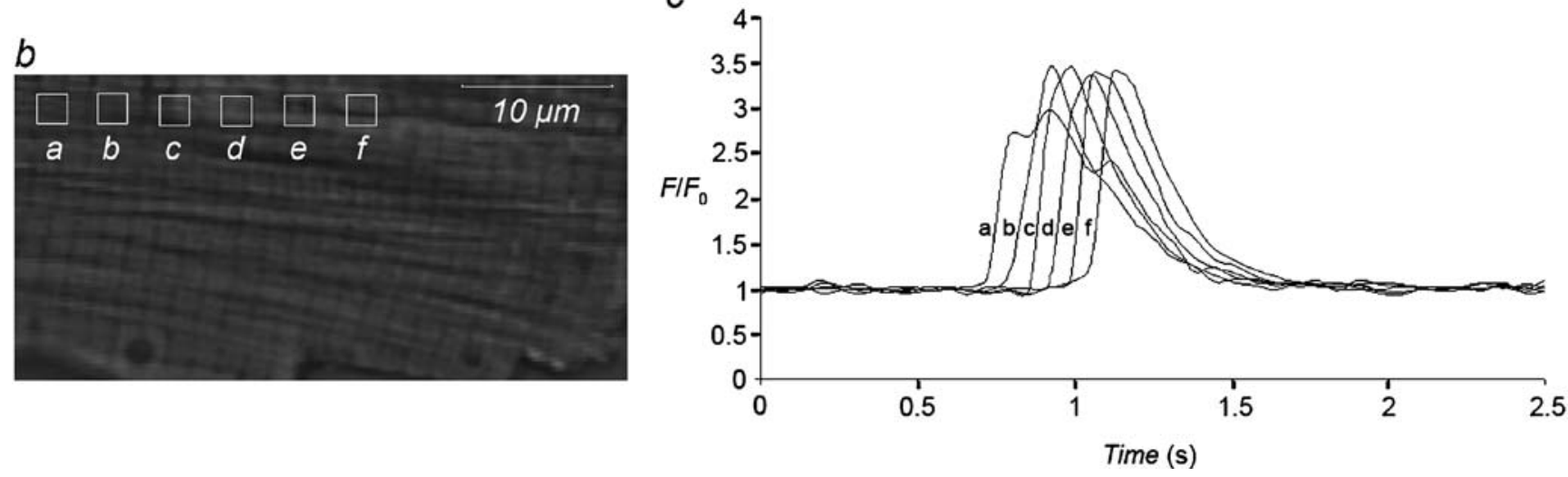

Fig. 8 Successive frame scan images demonstrate propagation of a $\mathrm{Ca}^{2+}$ wave from one end of the cell to the other, moving along the axis of the cell, from left to right in this view (a). The presence of 8-CPT resulted in the spontaneous appearance of such travelling waves in resting isolated myocytes in 9 out of 16 of myocytes. In contrast, under control conditions, myocytes never showed such events $(P<$ 0.001 , Fisher's exact test; $n=16$ and 20, 8-CPT-treated and control

$\mathrm{Ca}^{2+}$ wave induced by 8 -CPT perfusion reveals this spatiotemporal pattern of $\mathrm{Ca}^{2+}$ release (Fig. 8a). These phenomena could be analysed by a comparison of $F / F_{0}$ signals with time through regions of interest (ROIs) placed at regular intervals along the long axis of the cell being examined (Fig. 8b). These ROIs yielded $F / F_{0}$ traces with progressively increasing latencies but otherwise similar increases in intensity once such waves were established (Fig. 7c). Such $\mathrm{Ca}^{2+}$ waves travelled at a constant velocity of $102.6 \pm$ $14.1 \mu \mathrm{m} \mathrm{s}^{-1}(n=9)$, in close agreement to previously reported
velocities of resting $\mathrm{Ca}^{2+}$ waves in rat ventricular myocytes 4

\section{.}


[50]. $\mathrm{Ca}^{2+}$ waves are thought to exert arrhythmogenic effects by producing $I_{\mathrm{ti}}$ that itself underlies DADs, in turn leading to triggered arrhythmias [6, 38, 50]. In such an event, the observed $\mathrm{Ca}^{2+}$ waves in the presence of 8-CPT could be a cellular manifestation of the proarrhythmic effects of 8-CPT. Such cytosolic $\mathrm{Ca}^{2+}$ waves were also consistent with the arrhythmogenic $\mathrm{Ca}^{2+}$ waves induced by caffeine in a previous murine model of triggered ventricular arrhythmogenesis [4].

CaMKII inhibition prevents Epac-mediated abnormalities of $\mathrm{Ca}^{2+}$ handling

Finally, in parallel with the antiarrhythmic effects CaMKII inhibition at the level of whole hearts, CaMKII inhibition also inhibited Epac-mediated changes in cellular $\mathrm{Ca}^{2+}$ handling in the following experiments.

Firstly, in paced cells, pretreatment with KN-93 was not associated with ectopic $\mathrm{Ca}^{2+}$ transients $(n=14)$ and therefore yielded results similar to control conditions (Fig. 7d). However, cells treated with both 8 -CPT and KN-93 also failed to trigger ectopic $\mathrm{Ca}^{2+}$ transients $(n=14)$. This prevention of Epac-mediated ectopic $\mathrm{Ca}^{2+}$ transients by KN-93 occurred without any change in peak $F / F_{0}$ (Tables 2 and 3).

Secondly, in resting cells, pretreatment with KN-93 was not associated with spontaneous $\mathrm{Ca}^{2+}$ transients in any cells $(n=15)$. Furthermore, KN-93 pretreatment significantly reduced the incidence of spontaneous $\mathrm{Ca}^{2+}$ transients in cells co-treated with KN-93 and 8-CPT, with ectopic $\mathrm{Ca}^{2+}$ signals seen in only 2 out of 16 cells. Thus, compared to cells treated with 8-CPT alone, KN-93 significantly reduced Epac-dependent spontaneous $\mathrm{Ca}^{2+}$ transients in resting myocytes $(P<0.01$, Fisher's exact test).

\section{Discussion}

Cardiac $\beta$-adrenergic signalling has been classically explained in terms of a PKA-dependent signalling pathway [7] activated by $\beta$-adrenoreceptor stimulation that involves receptor binding of the ligand, $\mathrm{G}_{\mathrm{s}}$-protein and, consequently, adenylate cyclase activation, resulting in an elevation of cytosolic cAMP and its activation of PKA. The increased activity of PKA is suggested to phosphorylate RyR2 possibly at a key serine residue, thereby increasing RyR2 open probabilities and therefore diastolic $\mathrm{Ca}^{2+}$ leak in cardiac myocytes leading to the arrhythmogenic effects associated with catecholaminergic action in whole hearts [57-59]. However, since the identification of Epac [16, 26], cAMP-dependent, PKA-independent effects have also been reported in different cell types, including pancreatic, neuronal and cardiac cells [9].
We directly demonstrate, for the first time to our knowledge that Epac activation results in ventricular arrhythmogenesis in the whole mouse heart and relate these to findings at the cellular level and complement recent results from the rat at the cellular level [36].

As in previous studies of cAMP-dependent, PKAindependent processes, we used two pharmacological approaches to dissect out cAMP-dependent, PKA-independent processes $[9,34]$. The recent development of a membrane permeant cAMP analogue, 8-pCPT-2'-O-Me-cAMP (8-CPT) [19], provided selective Epac activation through a mechanism independent of either PKA or LTCC modification at the concentrations used here $[19,25,36]$. We used a lower dose $(1 \mu \mathrm{M})$ of 8 -CPT than used previously $[34,36]$ to minimise nonspecific and nonphysiological effects. Although the affinity of cAMP for Epac1 in vitro has been reported in the micromolar range $[9,40]$ in contrast to a nanomolar affinity of cAMP binding to PKA [56], other reports, also in vitro, show that the $K_{\mathrm{d}}$ for cAMP binding to PKA and Epac1 are similar, $2.8 \mu \mathrm{M}$ for Epac1 [11] and $2.9 \mu \mathrm{M}$ for PKA [14]. Furthermore, recent studies employing Epac-based FRET probes demonstrated micromolar fluctuations in [cAMP] following agents known to stimulate its cellular production, suggesting their capacity to activate Epac in vivo $[17,28,33,39]$. The effects of 8-CPT described in this study were confirmed by activating Epac with a second pharmacological method. Thus, PKA was inhibited using H-89, in combination with isoproterenol to stimulate production of Epac's physiological activator, cAMP, as also used previously [34].

We thus report for the first time that the Epac-activated murine heart is capable of generating triggered activity and spontaneously initiating and maintaining VT and showing an increased tendency to provoked VT through the use of PES, an electrophysiological test adapted from clinical practice $[27,35,47]$. Such arrhythmogenesis resulted in the development of multiple ECG waveforms that progressed from a regular rhythm, through a monomorphic VT, to VF that was in common with a similar sequence in the human case [60]. In addition, such ECG analysis demonstrated that Epac-activation also results in a sustained bidirectional VT. The latter has been observed clinically in CPVT and in an arrhythmogenic mouse model of CPVT associated with underlying abnormalities of $\mathrm{Ca}^{2+}$ homeostasis with evidence of a triggered as opposed to reentrant mechanism of arrhythmia $[10,31]$.

These observed electrophysiological features differed significantly from those associated with gene mutations in ion channels associated with increases in epicardial $\mathrm{APD}_{90}$, in turn leading to altered negative $\triangle \mathrm{APD}_{90} \mathrm{~s}$ and increased frequencies of EADs owing to consequent window currents of LTCC reactivation [24]. These occur in murine models of long QT syndromes (LQTS) 3 and 5 and hypokalaemic 
conditions and result in an arrhythmogenesis that has been attributed to triggered and reentrant excitation in the free wall of the left ventricle $[27,51,53]$. Subsequent studies had further explored for and demonstrated criteria for reentrant excitation [44] generated by increases in $\mathrm{APD}_{90}$ relative to VERP values. In addition, temporal factors such as the relationship between $\mathrm{BCL}$ and $\mathrm{APD}_{90}$, $\mathrm{APD}$ alternans, and $\mathrm{APD}_{90}$ restitution [46] have been proposed as predictors of arrhythmia in murine models of LQTS.

However, the arrhythmogenic phenomena described here took place in the absence of such electrophysiological predictors. Thus, the Epac-mediated arrhythmias occurred in the absence of prolonged epicardial $\mathrm{APD}_{90}$ whilst endocardial $\mathrm{APD}_{90}$ values were preserved. This consequently led to a normal $\triangle \mathrm{APD}_{90}$. Furthermore, there were no alterations in VERP suggesting an unaltered relationship between VERP and epicardial $\mathrm{APD}_{90}$. Temporal properties reflected in $\mathrm{APD}_{90}$ restitution revealed no increase in the maximum gradient of the restitution curve. In addition, the apico-basal gradient of repolarisation was preserved in the observed arrhythmogenesis.

Such arrhythmogenic features were instead associated with significant abnormalities in $\mathrm{Ca}^{2+}$ handling at the cellular level complementing previous reports correlating arrhythmogenic tendency with alterations in $\mathrm{Ca}^{2+}$ handling. These acute effects are additional to reported involvements of Epac activation in cardiac hypertrophy [32] with potential long-term effects on the development of arrhythmogenic tendency [47] in rat neonatal cardiomyocytes. Thus, experiments at the cellular level demonstrated a significantly increased incidence of ectopic $\mathrm{Ca}^{2+}$ release in both paced and resting cells after Epac activation. They further showed a propensity to the generation of spontaneous $\mathrm{Ca}^{2+}$ waves, which had previously been associated with triggered cardiac arrhythmogenesis through the generation of $I_{\mathrm{ti}}$, which is thought to underlie DADs, in turn underlying triggered mechanisms of VT $[6,38]$. The observed alterations in $\mathrm{Ca}^{2+}$ handling due to Epac activation by both methods occurred without significant alterations in peak $F / F_{0}$. This allowed an assessment of whether ectopic $\mathrm{Ca}^{2+}$ release correlated with arrhythmogenic propensity. Previous reports using Epac activation with $10 \mu \mathrm{M}$ 8-CPT gave conflicting alterations in peak $F / F_{0}[34,36]$. Nevertheless, a previous study using $1 \mu \mathrm{M}$ 8-CPT similarly showed no change in the peak amplitude of spontaneous $\mathrm{Ca}^{2+}$ oscillations in cultured rat cardiomyocytes [32]. These results also complement recent reports confined to single ventricular myocytes rather than whole hearts that had demonstrated cAMP-dependent, PKA-independent alterations in $\mathrm{Ca}^{2+}$ handling in cardiac myocytes. They also demonstrated that Epac activation increases diastolic $\mathrm{Ca}^{2+}$ leak measured as $\mathrm{Ca}^{2+}$ sparks [36] and contributes to isoproterenol-induced alterations in $\mathrm{Ca}^{2+}$ handling [34]. Another report has demonstrated $\beta$-adrenergic diastolic $\mathrm{Ca}^{2+}$ leak that is independent of PKA whilst not directly implicating Epac [13].

Together, these findings are consistent with a distinct class of arrhythmogenic mechanisms associated with normal $\mathrm{APD}_{90}, \triangle \mathrm{APD}_{90}$ and VERP, but abnormal cytosolic $\mathrm{Ca}^{2+}$ homeostasis. They are compatible with speculative schemes in which arrhythmia is initiated and maintained by ectopic foci, as has been documented in human ventricular arrhythmias [37] and in the mouse [10]. These may involve micro-dispersions of refractoriness and repolarisation that cannot be detected with the methods used in this study. Alternatively, the increased ectopic $\mathrm{Ca}^{2+}$ release induced by Epac activation may possibly serve as the initiator for arrhythmias and their maintenance, through the increased frequency of action potentials further maintaining the SR $\mathrm{Ca}^{2+}$ load during any ensuing arrhythmia (see review by ter Keurs and Boyden [50]). In addition, a rise in $\mathrm{Ca}^{2+}$ can decrease the conduction velocity of an activation wavefront [29]. A local rise in $\mathrm{Ca}^{2+}$ could in this way produce functional block allowing the generation of a reentrant circuit. Furthermore, computer simulations of spiral waves show that nonuniformities of $\mathrm{Ca}^{2+}$ transients result in destabilisation of the spiral waves [12] producing fibrillation. These possibilities whether involving the SR and possibly also mitochondrial function [15] merit future investigation.

Finally, our results demonstrate that both the arrhythmogenesis and the altered $\mathrm{Ca}^{2+}$ handling due to Epac activation are significantly decreased by CaMKII inhibition. CaMKII has multiple targets [1] of which the LTCC and $\mathrm{Na}^{+}$channel could affect the action potential waveform and refractory period, alterations in which are required to establish the alternative LQTS-type reentrant arrhythmogenic mechanism [27, 44, 53]. However, Epac activation does not appear to alter $I_{\mathrm{Ca}}$ nor APD [36]. A previous report has shown increases in late $\mathrm{Na}^{+}$current and rate-dependent increases in $\mathrm{APD}_{90}$ relative to control in a mouse model of CaMKII overexpression [55]. However, our results in acute wild-type preparations do not show such changes in action potential waveform whether with the initiation by Epac activation by two independent methods, or in its rescue by $\mathrm{KN}-93$. Instead, we demonstrate changes in $\mathrm{Ca}^{2+}$ handling, accordingly likely due to altered RyR2 properties demonstrated previously by increased phosphorylation at the CaMKII RyR2 site together with an increased spark frequency [36] and consistent with the reported functional coupling of Epac with the RyR2 [9, 18]. Our findings accordingly further complement a previous report showing that $\mathrm{Ca}^{2+}$ sparks in cardiac myocytes after Epac activation are prevented by CaMKII inhibition [36]. This is compatible with an Epac-mediated VT driven primarily by altered 
$\mathrm{Ca}^{2+}$ handling due to altered RyR2 properties with consequent triggered arrhythmogenesis.

A role for Epac activation in physiological or at least pathophysiological processes thus merits attention. These features resemble arrhythmogenic phenomena known to take place in the absence of reentrant substrate under other circumstances that lead to alterations in $\mathrm{Ca}^{2+}$ homeostasis. Thus arrhythmogenesis in the mouse heart is brought about by addition of either caffeine or isoprenaline, both known to alter $\mathrm{Ca}^{2+}$ homeostasis at the cellular level $[4,5]$.

The findings reported here also have implications for the growing views that both cAMP signalling in general [16, $22,26]$ and $\beta$-adrenergic stimulation leading to RyR2 activation as a specific example, are mediated by two pathways. The latter have been broadly divided into both PKA-dependent and PKA-independent mechanisms [13, $34,36]$. We suggest that the PKA-independent cAMPdependent pathways include an Epac-mediated mechanism within the cAMP-dependent signalling pathway complementary to but not excluding PKA-mediated RyR2 activation in $\mathrm{Ca}^{2+}$-mediated arrhythmogenesis [57-59] in conditions such as CPVT and triggered aspects of HF [38]. Thus, future work focussing on the role of Epac may contribute to an improved understanding of cardiac physiology and explain current discrepancies in hypotheses relying solely on the classical cAMP pathway.

These comparisons in murine systems also translate to clinical observations. Thus, whilst changes in overall repolarisation gradients may correlate with changes in QT interval and have been implicated in arrhythmogenic substrate in LQTS [41], patients with CPVT associated with genetic defects in the RyR2 and CasQ [31] have a normal QT interval [49], and so a normal gradient of repolarisation as observed here is in keeping with the clinical features and diagnostic criteria. Involvement of Epac in ventricular tachycardia as demonstrated here also suggests the need for further research into the possibility that it may be a novel therapeutic target, particularly in HF and CPVT. There are therefore potentially important clinical implications of the research findings presented here, warranting further investigation.

Acknowledgements We thank the Medical Research Council, the Wellcome Trust, the British Heart Foundation, Helen Kirkland Trust, Papworth Hospital, UK and Trinity College, Cambridge for their generous support. SSH holds an Official Fellowship and College Lectureship at New Hall, Cambridge and was supported by a MRC Capacity Building Award to CLH. SWB was supported by a Wellcome Trust Studentship.

Open Access This article is distributed under the terms of the Creative Commons Attribution Noncommercial License which permits any noncommercial use, distribution, and reproduction in any medium, provided the original author(s) and source are credited.

\section{References}

1. Anderson ME (2007) Multiple downstream proarrhythmic targets for calmodulin kinase II: Moving beyond an ion channel-centric focus. Cardiovasc Res 73:657-666

2. Anderson ME, Braun AP, Wu Y, Lu T, Wu Y, Schulman H, Sung RJ (1998) KN-93, an inhibitor of multifunctional $\mathrm{Ca}^{++} /$calmodulin-dependent protein kinase, decreases early afterdepolarizations in rabbit heart. J Pharmacol Exp Ther 287:996-1006

3. Baker LC, London B, Choi B-R, Koren G, Salama G (2000) Enhanced dispersion of repolarization and refractoriness in transgenic mouse hearts promotes reentrant ventricular tachycardia. Circ Res 86:396-407

4. Balasubramaniam R, Chawla S, Grace AA, Huang CL (2005) Caffeine-induced arrhythmias in murine hearts parallel changes in cellular $\mathrm{Ca}^{2+}$ homeostasis. Am J Physiol Heart Circ Physiol 289: H1584-H1593

5. Balasubramaniam R, Chawla S, Mackenzie L, Schwiening CJ, Grace AA, Huang CLH (2004) Nifedipine and diltiazem suppress ventricular arrhythmogenesis and calcium release in mouse hearts. Pflügers Arch 449:150-158

6. Berlin JR, Cannell MB, Lederer WJ (1989) Cellular origins of the transient inward current in cardiac myocytes. Role of fluctuations and waves of elevated intracellular calcium. Circ Res 65:115-126

7. Bers DM (2001) Excitation-contraction coupling and cardiac contractile force, 2nd edn. Kluwer Academic Publishers, Dordrecht, The Netherlands

8. Bers DM (2006) Cardiac ryanodine receptor phosphorylation: target sites and functional consequences. Biochem J 396:e1-e3

9. Bos JL (2006) Epac proteins: multi-purpose cAMP targets. Trends Biochem Sci 31:680-686

10. Cerrone M, Noujaim SF, Tolkacheva EG, Talkachou A, O’Connell R, Berenfeld O, Anumonwo J, Pandit SV, Vikstrom K, Napolitano C, Priori SG, Jalife J (2007) Arrhythmogenic mechanisms in a mouse model of catecholaminergic polymorphic ventricular tachycardia. Circ Res 101:1039-1048

11. Christensen AE, Selheim F, de Rooij J, Dremier S, Schwede F, Dao KK, Martinez A, Maenhaut C, Bos JL, Genieser HG, Doskeland SO (2003) cAMP analog mapping of Epac1 and cAMP kinase. Discriminating analogs demonstrate that Epac and cAMP kinase act synergistically to promote PC-12 cell neurite extension. J Biol Chem 278:35394-35402

12. Chudin E, Garfinkel A, Weiss J, Karplus W, Kogan B (1998) Wave propagation in cardiac tissue and effects of intracellular calcium dynamics (computer simulation study). Prog Biophys Mol Biol 69:225-236

13. Curran J, Hinton MJ, Rios E, Bers DM, Shannon TR (2007) $\beta$ adrenergic enhancement of sarcoplasmic reticulum calcium leak in cardiac myocytes is mediated by calcium/calmodulin-dependent protein kinase. Circ Res 100:391-398

14. Dao KK, Teigen K, Kopperud R, Hodneland E, Schwede F, Christensen AE, Martinez A, Doskeland SO (2006) Epac1 and cAMP-dependent protein kinase holoenzyme have similar cAMP affinity, but their cAMP domains have distinct structural features and cyclic nucleotide recognition. J Biol Chem 281:21500-21511

15. de J Garcia-Rivas G, Carvajal K, Correa F, Zazueta C (2006) Ru360, a specific mitochondrial calcium uptake inhibitor, improves cardiac post-ischaemic functional recovery in rats in vivo. Br J Pharmacol 149:829-837

16. de Rooij J, Zwartkruis FJT, Verheijen MHG, Cool RH, Nijman SMB, Wittinghofer A, Bos JL (1998) Epac is a Rap1 guaninenucleotide-exchange factor directly activated by cyclic AMP. Nature 396:474-477

17. DiPilato LM, Cheng X, Zhang J (2004) Fluorescent indicators of cAMP and Epac activation reveal differential dynamics of cAMP 
signaling within discrete subcellular compartments. Proc Natl Acad Sci USA 101:16513-16518

18. Dodge-Kafka KL, Soughayer J, Pare GC, Carlisle Michel JJ, Langeberg LK, Kapiloff MS, Scott JD (2005) The protein kinase A anchoring protein $\mathrm{mAKAP}$ coordinates two integrated cAMP effector pathways. Nature 437:574-578

19. Enserink JM, Christensen AE, de Rooij J, van Triest M, Schwede F, Genieser HG, Doskeland SO, Blank JL, Bos JL (2002) A novel Epac-specific cAMP analogue demonstrates independent regulation of Rap1 and ERK. Nat Cell Biol 4:901-906

20. Fabritz L, Kirchhof P, Franz MR, Nuyens D, Rossenbacker T, Ottenhof A, Haverkamp W, Breithardt G, Carmeliet E, Carmeliet $P$ (2003) Effect of pacing and mexiletine on dispersion of repolarisation and arrhythmias in $\triangle \mathrm{KPQ}$ SCN5A (long QT3) mice. Cardiovasc Res 57:1085-1093

21. Giles W, Shimoni Y (1989) Comparison of sodium-calcium exchanger and transient inward currents in single cells from rabbit ventricle. J Physiol 417:465-481

22. Holz GG, Kang G, Harbeck M, Roe MW, Chepurny OG (2006) Cell physiology of cAMP sensor Epac. J Physiol 577:5-15

23. January CT, Fozzard HA (1988) Delayed afterdepolarizations in heart muscle: mechanisms and relevance. Pharmacol Rev 40:219227

24. January CT, Riddle JM (1989) Early afterdepolarizations: mechanism of induction and block. A role for L-type $\mathrm{Ca}^{2+}$ current. Circ Res 64:977-990

25. Kang G, Holz GG (2003) Amplification of exocytosis by $\mathrm{Ca}^{2+}$ induced $\mathrm{Ca}^{2+}$ release in INS-1 pancreatic beta cells. J Physiol 546:175-89

26. Kawasaki H, Springett GM, Mochizuki N, Toki S, Nakaya M, Matsuda M, Housman DE, Graybiel AM (1998) A family of cAMP-binding proteins that directly activate Rap1. Science 282:2275-2279

27. Killeen MJ, Thomas G, Gurung IS, Goddard CA, Fraser JA, Mahaut-Smith MP, Colledge WH, Grace AA, Huang CL (2007) Arrhythmogenic mechanisms in the isolated perfused hypokalaemic murine heart. Acta Physiol (Oxf) 189:33-46

28. Landa LR Jr., Harbeck M, Kaihara K, Chepurny O, Kitiphongspattana K, Graf O, Nikolaev VO, Lohse MJ, Holz GG, Roe MW (2005) Interplay of $\mathrm{Ca}^{2+}$ and cAMP signaling in the insulinsecreting MIN6 beta-cell line. J Biol Chem 280:31294-302

29. Luscher C, Lipp P, Luscher HR, Niggli E (1996) Control of action potential propagation by intracellular $\mathrm{Ca}^{2+}$ in cultured rat dorsal root ganglion cells. J Physiol 490:319-324

30. Makaula S, Lochner A, Genade S, Sack MN, Awan MM, Opie LH (2005) H-89, a non-specific inhibitor of protein kinase A, promotes post-ischemic cardiac contractile recovery and reduces infarct size. J Cardiovasc Pharmacol 45:341-7

31. Mohamed U, Napolitano C, Priori SG (2007) Molecular and electrophysiological bases of catecholaminergic polymorphic ventricular tachycardia. J Cardiovasc Electrophysiol 18:791-797

32. Morel E, Marcantoni A, Gastineau M, Birkedal R, Rochais F, Garnier A, Lompre AM, Vandecasteele G, Lezoualc'h F (2005) cAMP-binding protein Epac induces cardiomyocyte hypertrophy. Circ Res 97:1296-304

33. Nikolaev VO, Bunemann M, Hein L, Hannawacker A, Lohse MJ (2004) Novel single chain cAMP sensors for receptor-induced signal propagation. J Biol Chem 279:37215-37218

34. Oestreich EA, Wang H, Malik S, Kaproth-Joslin KA, Blaxall BC, Kelley GG, Dirksen RT, Smrcka AV (2007) Epac-mediated activation of phospholipase C(epsilon) plays a critical role in beta-adrenergic receptor-dependent enhancement of $\mathrm{Ca}^{2+}$ mobilization in cardiac myocytes. J Biol Chem 282:5488-5495

35. Papadatos GA, Wallerstein PM, Head CE, Ratcliff R, Brady PA, Benndorf K, Saumarez RC, Trezise AE, Huang CL, Vandenberg JI, Colledge WH, Grace AA (2002) Slowed conduction and ventricular tachycardia after targeted disruption of the cardiac sodium channel gene Scn5a. Proc Natl Acad Sci USA 99:6210-6215

36. Pereira L, Metrich M, Fernandez-Velasco M, Lucas A, Leroy J, Perrier R, Morel E, Fischmeister R, Richard S, Benitah J-P, Lezoualc'h F, Gomez AM (2007) The cAMP binding protein Epac modulates $\mathrm{Ca}^{2+}$ sparks by a $\mathrm{Ca}^{2+} /$ calmodulin kinase signalling pathway in rat cardiac myocytes. J Physiol 583:685694

37. Pogwizd SM (1994) Focal mechanisms underlying ventricular tachycardia during prolonged ischemic cardiomyopathy. Circulation 90:1441-158

38. Pogwizd SM, Bers DM (2004) Cellular basis of triggered arrhythmias in heart failure. Trends Cardiovasc Med 14:61-66

39. Ponsioen B, Zhao J, Riedl J, Zwartkruis F, van der Krogt G, Zaccolo M, Moolenaar WH, Bos JL, Jalink K (2004) Detecting cAMP-induced Epac activation by fluorescence resonance energy transfer: Epac as a novel cAMP indicator. EMBO Rep 5:11761180

40. Rehmann H, Schwede F, Doskeland SO, Wittinghofer A, Bos JL (2003) Ligand-mediated activation of the cAMP-responsive guanine nucleotide exchange factor Epac. J Biol Chem 278:38548-38556

41. Restivo M, Caref EB, Kozhevnikov DO, El-Sherif N (2004) Spatial dispersion of repolarization is a key factor in the arrhythmogenicity of long QT syndrome. J Cardiovasc Electrophysiol 15:323-331

42. Rosenbaum DS, Jackson LE, Smith JM, Garan H, Ruskin JN, Cohen RJ (1994) Electrical alternans and vulnerability to ventricular arrhythmias. N Engl J Med 330:235-241

43. Ruberman W, Weinblatt E, Goldberg JD, Frank CW, Shapiro S (1977) Ventricular premature beats and mortality after myocardial infarction. N Engl J Med 297:750-757

44. Sabir IN, Fraser JA, Killeen MJ, Grace AA, Huang CL (2007) The contribution of refractoriness to arrhythmic substrate in hypokalemic Langendorff-perfused murine hearts. Pflugers Arch 454:209-222

45. Sabir IN, Li LM, Grace AA, Huang CL (2007) Restitution analysis of alternans and its relationship to arrhythmogenicity in hypokalaemic Langendorff-perfused murine hearts. Pflugers Arch 455:653-666

46. Sabir IN, Li LM, Jones VJ, Goddard CA, Grace AA, Huang CL (2007) Criteria for arrhythmogenicity in genetically-modified Langendorff-perfused murine hearts modelling the congenital long QT syndrome type 3 and the Brugada syndrome. Pflugers Arch 455(4):637-651

47. Saumarez RC, Grace AA (2000) Paced ventricular electrogram fractionation and sudden death in hypertrophic cardiomyopathy and other non-coronary heart diseases. Cardiovasc Res 47:11-22

48. Schram G, Pourrier M, Melnyk P, Nattel S (2002) Differential distribution of cardiac ion channel expression as a basis for regional specialization in electrical function. Circ Res 90:939-950

49. Sumitomo N, Harada K, Nagashima M, Yasuda T, Nakamura Y, Aragaki Y, Saito A, Kurosaki K, Jouo K, Koujiro M, Konishi S, Matsuoka S, Oono T, Hayakawa S, Miura M, Ushinohama H, Shibata T, Niimura I (2003) Catecholaminergic polymorphic ventricular tachycardia: electrocardiographic characteristics and optimal therapeutic strategies to prevent sudden death. Heart 89:66-70

50. ter Keurs HEDJ, Boyden PA (2007) Calcium and arrhythmogenesis. Physiol Rev 87:457-506

51. Thomas G, Gurung IS, Killeen MJ, Hakim P, Goddard CA, Mahaut-Smith MP, Colledge WH, Grace AA, Huang CL (2007) Effects of L-type $\mathrm{Ca}^{2+}$ channel antagonism on ventricular arrhythmogenesis in murine hearts containing a modification in the Scn $5 a$ gene modelling human long QT syndrome 3. J Physiol 578:85-97 
52. Thomas G, Killeen MJ, Grace AA, Huang CLH (2007) Pharmacological separation of early afterdepolarizations from arrhythmogenic substrate in $\triangle \mathrm{KPQ}$ Scn5a murine hearts modelling human long QT 3 syndrome. Acta Physiol (Oxf) 192:505-517

53. Thomas G, Killeen MJ, Gurung IS, Hakim P, Balasubramaniam R, Goddard CA, Grace AA, Huang CL (2007) Mechanisms of ventricular arrhythmogenesis in mice following targeted disruption of KCNE1 modelling long QT syndrome 5. J Physiol 578:99-114

54. Tomaselli GF, Zipes DP (2004) What causes sudden death in heart failure? Circ Res 95:754-763

55. Wagner S, Dybkova N, Rasenack EC, Jacobshagen C, Fabritz L, Kirchhof P, Maier SK, Zhang T, Hasenfuss G, Brown JH, Bers DM, Maier LS (2006) $\mathrm{Ca}^{2+} /$ calmodulin-dependent protein kinase II regulates cardiac $\mathrm{Na}^{+}$channels. J Clin Invest 116:3127-3138

56. Walsh DA, Perkins JP, Krebs EG (1968) An adenosine $3^{\prime}, 5^{\prime}-$ monophosphate-dependant protein kinase from rabbit skeletal muscle. J Biol Chem 243:3763-3765

57. Wehrens XH, Lehnart SE, Marks AR (2005) Intracellular calcium release and cardiac disease. Annu Rev Physiol 67:69-98

58. Wehrens XH, Lehnart SE, Reiken S, Vest JA, Wronska A, Marks AR (2006) Ryanodine receptor/calcium release channel PKA phosphorylation: a critical mediator of heart failure progression. Proc Natl Acad Sci USA 103:511-518

59. Wehrens XHT, Lehnart SE, Huang F, Vest JA, Reiken SR, Mohler PJ, Sun J, Guatimosim S, Song L-S, Rosemblit N, D'Armiento JM, Napolitano C, Memmi M, Priori SG, Lederer WJ, Marks AR (2003) FKBP12.6 deficiency and defective calcium release channel (ryanodine receptor) function linked to exercise-induced sudden cardiac death. Cell 113:829-840

60. Weiss JN, Chen P-S, Qu Z, Karagueuzian HS, Garfinkel A (2000) Ventricular fibrillation: how do we stop the waves from breaking? Circ Res 87:1103-1107

61. Xiao B, Sutherland C, Walsh MP, Chen SRW (2004) Protein kinase A phosphorylation at serine-2808 of the cardiac $\mathrm{Ca}^{2+}$ release channel (ryanodine receptor) does not dissociate $12.6-\mathrm{kDa}$ FK506-binding protein (FKBP12.6). Circ Res 94:487-495

62. Xiao B, Zhong G, Obayashi M, Yang D, Chen K, Walsh MP, Shimoni Y, Cheng H, Ter Keurs H, Chen SR (2006) Ser-2030, but not Ser-2808, is the major phosphorylation site in cardiac ryanodine receptors responding to protein kinase A activation upon beta-adrenergic stimulation in normal and failing hearts. Biochem J 396:7-16 